Review

\title{
Synthesis and applications of hierarchically porous catalysts
}

\author{
LI Xiaoyun a,b,†, SUN Minghui a, ${ }^{a}$, ROOKE Joanna Claire ${ }^{b}$, CHEN Lihua ${ }^{a, \#, ~ S U ~ B a o-L i a n ~ a, b, c, * ~}$ \\ a State Key Laboratory of Advanced Technology for Material Synthesis and Processing, Wuhan University of Technology, Wuhan 430070, Hubei, China \\ ${ }^{\mathrm{b}}$ Laboratory of Inorganic Materials Chemistry (CMI), University of Namur (FUNDP), 61, rue de Bruxelles, B-5000 Namur, Belgium \\ c Department of Chemistry, University of Cambridge, Lensfield Road, Cambridge CB2 1EW, UK
}

\section{A R T I C L E I N F O}

\section{Article history:}

Received 20 December 2012

Accepted 29 December 2012

Published 20 January 2013

Keywords:

Hierarchically porous structure

Zeolite

Metal oxide

Carbon-based

\begin{abstract}
A B S T R A C T
Hierarchically porous materials that can be used as catalysts or catalyst supports have garnered much attention due to their enhanced mass transport and multiple functionalities. Hierarchically porous catalysts integrate at least two levels of porosity and present the advantages associated with each level of porosity, from selectivity to mass transport. For example, hierarchically porous zeolites offer an effective solution to the mass transport problem associated with conventional zeolites in catalyzed reactions, because they combine the catalytic features of micropores and the improved accessibility and increased molecular transport related to the addition of several porosities within a single body. This review thoroughly summarizes recent developments that have been made in the field of hierarchically porous catalysts, with the main focus on the synthesis strategies that are available as well as their application in catalysis. It is the intent of this work to stimulate intuition into the optimal design of related hierarchically porous catalysts with desired characteristics.
\end{abstract}

(C) 2013, Dalian Institute of Chemical Physics, Chinese Academy of Sciences. Published by Elsevier B.V. All rights reserved.

\section{Introduction}

Over the last decade, significant interest has been devoted to the synthesis and application of hierarchically porous materials [1-9], which contain a porous structure consisting of multiple levels of porosities on different length scales from micro-, meso- to macropores. Micro-mesopores with uniform pore size will provide the size and shape selectivity for guest molecules, enhancing host-guest interactions. The presence of macropores can considerably favor the diffusion to and the accessibility of the active sites by guest molecules $[10,11]$. Hierarchically porous structure will improve the mass transport, which is particularly important for the diffusion of large molecules or in viscous systems in various catalytic reactions. This kind of materials can reduce the coke deposition and even improve the tolerance of coke deposition, increasing thus the catalyst lifetime due to the easy mass transport and the large pore volume of macroporous systems, respectively. Hierarchically structuring both the porosity and the architecture of a material over different length scales has provided the opportunity to render materials suitable for a variety of functions that are desirable in a large series of applications, such as catalysis, separation, optics, energy, and biomedicine to life science [12].

Recently, hierarchically porous materials that can be used as catalysts or catalyst supports have attached much attention due to their enhanced mass transport and multiple functionalities [13]. Catalytic processes are composed of pretreatment, chemical conversion, and purification of final products, in which a defined catalyst could be utilized to accelerate the processes and improve the conversion rate from reactants to resultant

\footnotetext{
* Corresponding author. Tel: +32-81-724531; Fax: +32-81-725414; E-mail: bao-lian.su@fundp.ac.be

\# Corresponding author. Tel/Fax: +86-27-87855322; E-mail: chenlihua@whut.edu.cn

$\dagger$ These authors contributed equally to this work.

This work was supported by Changjiang Scholars and Innovative Research Team in University (IRT1169) and an InterregIVa REDUGAZ France-Wallonie-Flandre project supported by the European community and Wallonia government. DOI: 10.1016/S1872-2067(11)60507-X
} 
products. Hierarchically porous catalysts present many advantages during catalytic process due to their improved mass transport and tunable catalytically active sites in comparison with conventional catalysts, including the reduction of reaction steps involved energy conservation, less by-products, increased operational safety, and so on $[14,15]$. The integration of multimodal porosities that could be individually functionalized within one single body could potentially allow for the successive realization of a complete reaction from starting reagents to the final desired products. Separation and purification processes would inherently take place owing to the sieving capacity of the multipore system, such that the product of one reaction can become the reagent for the next reaction [16,17]. A novel concept "Hierarchical Catalysis" was thus proposed by Su et al $[12,15,18]$. The concrete example of hierarchically porous zeolite catalyst in use in industry is FCC catalyst with macroporous aluminosilicate amorphous clay supports and microporous USY zeolite containing mesoporosity. The concept of incorporation of multiporosity and multifunctionality was started from the work in RIPP (Research Institute of Petroleum Processing) under the supervision of Prof. Enze Min. We choose this subject in honor of Prof. Enze Min on the occasion of his 90th birthday to celebrate his contribution to the development of petroleum processing industry in China from zero to a very performance industry. In FCC catalyst, the different porosities were artificially incorporated and there is no interconnection between different porosities. The imperative to develop new approaches in the fabrication of bi-, or even tri-modal porous structures incorporated in one solid body with good interconnectivity between pores has pushed this research field to the forefront. Many successful methods have been developed to prepare hierarchically porous catalysts [19-21]. However, there is a great challenge to make full use of the advantages of hierarchically porous materials as catalysts or catalyst supported materials. In this paper, recent developments that have been achieved in the field of hierarchically porous materials, with the main review on the synthesis strategies and catalytic performances exhibited by the resultant hierarchically porous catalysts, will be thoroughly examined. Hierarchically porous catalysts can be classified according to their composition from hierarchically porous zeolites, hierarchically porous metal oxides, and hierarchically porous carbon-based catalysts. This review will illustrate the approaches that are now available, with examples from the literature given in more detail for each kind of hierarchically porous catalyst.

\section{Synthesis and applications of hierarchically porous catalysts}

Currently, a tremendous amount of hierarchically porous materials have been successfully developed by a series of technologies. The structural variables (such as atomic structure, molecular structure, nanostructure, and microstructure), compositional variables (such as stoichiometry and homogeneity), morphological variables (such as particle shape, grain size, and orientation distributions), and phase relations can be altered (although, for the most part, not independently) by the control of fabrication processes to hierarchically structured porous materials [12,18-22]. In this section, we thoroughly summarize recent developments that have been achieved in the field of hierarchically porous materials and their applications in catalysis. The hierarchically porous catalysts are classified into three categories according to their compositions: hierarchically porous zeolites, hierarchically porous metal oxides, and hierarchically porous carbon-based catalysts. These hierarchically porous catalysts have been introduced with the main focus on the synthesis strategies that are available and their catalytic applications in organic reactions, with examples given from the literature.

\subsection{Hierarchically porous zeolites}

Among the diverse porous materials used as catalysts, zeolites with intricate micropores have been widely used in industry as heterogeneous catalysts due to their superior thermal and hydrothermal stability and strong acidity [23]. For example, zeolite Beta, ZSM-5, and Y have been used as solid acid catalysts in the field of oil refining, petrochemistry, and organic synthesis $[24,25]$. However, with an increasing requirement for faster diffusion rates of reactants and higher conversion of bulky molecules, the relatively small micropores in zeolites strongly influence mass transport to and from the active sites located within these micropores, thus severely limiting the performance of industrial catalysts. One problem with catalyst particles used in fixed-bed reactors is catalyst deactivation. One well-known example is the use of zeolite catalysts in alkylation reactions where polymerization of an olefin into large molecular species that cannot diffuse out of the small micropores can block these pores thus restricting access to the active sites and polluting the catalyst. The discovery of mesoporous [26-28] and macroporous materials [29,30] with large and uniform pores was considered to be a totally novel methodology for solving the limitation of molecular diffusion and the problems arising from the conversion of bulky molecules. Therefore, it became desirable to synthesize mesoporous or macroporous materials with crystalline zeolite walls, which could combine the advantages of both meso-/macro-porous materials and zeolites. Introducing larger pores into zeolitic materials to form hierarchically porous zeolites to solve the diffusion limitations of traditional microporous zeolites has become a domain, which has attracted much attention [31,32]. As a consequence, a series of hierarchically porous zeolites have been successfully synthesized via different methods and subsequently used as solid acid or oxidation catalysts in various organic reactions [15]. This part briefly summarizes recent developments in hierarchically porous zeolites, with the main focus on the synthesized method and their catalytic applications.

\subsubsection{Acid catalysts}

Currently, most of the world's gasoline is produced by the fluidized catalytic cracking of a heavy fraction of petroleum using zeolite catalysts. Today over 65 percent of the tonnage of FCC catalysts sold in the USA contains ultrastable zeolite Y (or USY). Recently, many aluminosilicate-type zeolites with hier- 
archically porous structures have been successfully synthesized and used as solid acid catalysts in organic reactions, especially for bulky molecules. The formation of additional pores in zeolites has been extensively explored to create zeolites with enhanced pore accessibility and molecular transport, which has resulted in improvement in their catalytic performances.

\subsubsection{Hard-templating}

Hard-templating is a frequently employed method to prepare zeolite catalysts with hierarchically porous structures. Hierarchically mesoporous/macroporous zeolite catalysts can be synthesized by introducing mesoscale or macroscale solid templates into a synthetic system designed to produce microporous zeolites. Currently, the available hard-templates include carbon [33-52], aerogel [53-58], polystyrene spheres [59-70] and mesoporous silica spheres [71-83], and other templates [84-91].

Various carbon type materials have been used as hard-templates for the formation of hierarchically porous zeolite catalysts, including carbon nanoparticles, carbon nanotubes, carbon nanofibers, ordered mesoporous carbon, carbon black, carbon aerogel, and so on [33-52]. Jacobsen et al. [36] reported the first example of the synthesis of mesostructured zeolites using nanocarbon particles pretreated with acidic or alkaline solution as mesoporous templates (Fig. 1). They found that by using an excess amount of a zeolite gel, it is possible for the zeolite to grow around the carbon particles of the inert matrix. However, ZSM-5 zeolites with a cave-like mesoporosity were obtained after removing the carbon matrix by calcination, which seriously limits accessibility and mass transfer. A series of new mesoporous zeolitic materials have been developed via the use of carbon particles as a mesopore template [37,38]. To overcome the limitation of cave-like mesoporous structures, carbon nanotubes and carbon nanofiber have been successfully employed as mesoporous templates instead of carbon nanoparticles, resulting in straight and uniform mesoporous channels, which are open to the external surface in zeolite crystals $[39,51]$. It has been found that carbon nanofiber skeins are very promising candidates to act as secondary templates in the synthesis of mesoporous zeolite crystals. In addition, the tortuosity of the mesopores created using carbon black is much higher than for the mesopores templated with carbon nanofiber [40].

After the development of ordered mesoporous carbons with pore sizes of 2-10 nm (CMKs) via the use of ordered mesoporous silicas templates [52], it was suggested that these CMKs

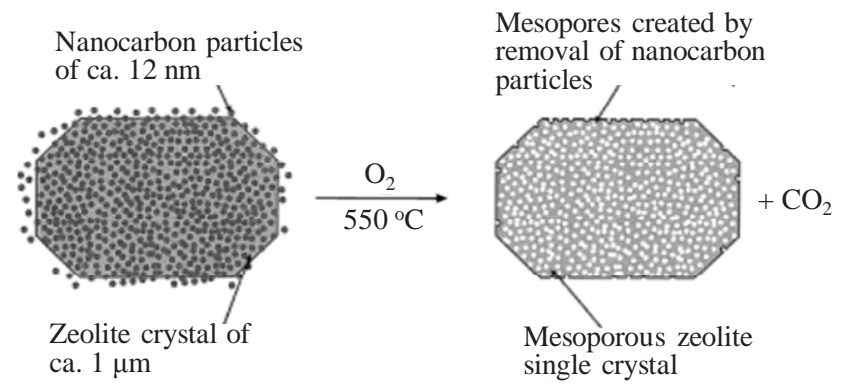

Fig. 1. Schematic illustration of the synthesis of mesoporous single crystal zeolites via nanocarbon particle templating [36]. could also be used as hard templates to produce zeolites that would copy the ordered mesostructure of CMKs. Many efforts have been made in this field [33,41-45]. For example, Yang et al. [41] reported for the first time on the preparation of ZSM-5 with unique supermicropores obtained by synthesizing a zeolite using well-ordered mesoporous carbon CMK-3 as a hard-template. Cho et al. [43] demonstrated the synthesis of mesoporous zeolite crystals, prepared by a solid state rearrangement process via the aid of a structure directing agent impregnated-ordered mesoporous precursor such as MCM-41 or SBA-15, containing nanostructured carbons in the pore channels. Unfortunately, the mesopores that formed in the crystals were always disordered, which might be due to the fact that the pore sizes of CMKs (in the range of 3-4 $\mathrm{nm}$ ) are too small to accommodate stable zeolite nanocrystals [41-45]. Moreover, a fragmentation phenomenon of the porous carbon occurred during the zeolite crystallization process, which led to the result that CMKs would fail to act as ordered mesoporous templates. In such cases, cave-like mesopores similar to the ones that formed using carbon nanoparticles were produced in the resultant zeolite crystals [42]. More recently, a novel route was reported for the preparation of mesopore with zeolite ZSM-5 via an in situ hydrothermal treatment of a solution containing alkali-dissolved SBA-15 containing carbonized surfactant P123 in the mesopores (Fig. 2) [45]. The resultant mesoZSM-5 was proved to be a remarkably stable and propylene-selective catalyst during the methanol to propylene (MTP) catalytic reaction. It has been discussed that the synthesis of ordered mesoporous zeolites using ordered mesoporous carbon as hard templates is difficult, which is strongly related to the wall thickness and free energy of each component. There is a claim for the preparation of an ordered mesoporous aluminosilicate with completely crystalline zeolite pore walls structure by recrystallization of SBA-15 using CMK- 5 formed in situ as the hard template [33]. However, the presence of both micropores and mesopores has yet to be confirmed because of the absence of direct TEM images. Significantly, when the walls of mesoporous zeolites are thick enough to stabilize zeolite nanocrystals, ordered zeolites can be synthesized. Fan et al. [34] reported a successful example for the synthesis of ordered cubic mesoporous silicalite-1 zeolites using ordered cubic mesoporous carbons (3DOm) as hard templates. On this basis, various zeolites, including BEA, LTA, FAU, and LTL, with three-dimensionally ordered mesoporous-imprinted structures

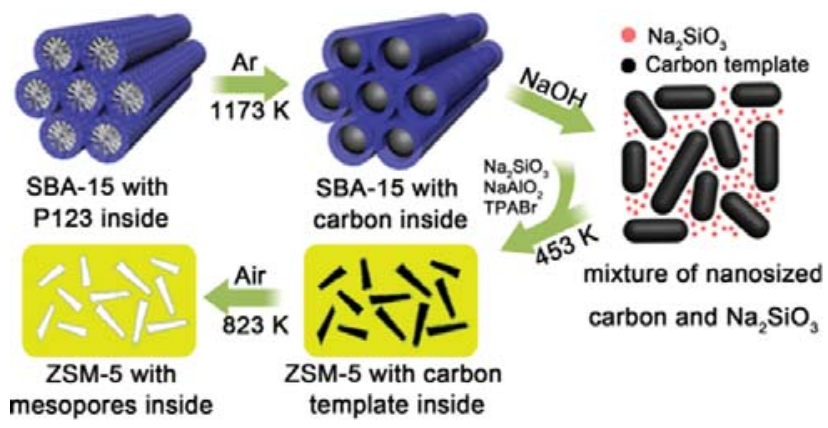

Fig. 2. Schematic illustration of the synthesis of mesoporous single crystal zeolites synthesised using a carbon nanotube template [45]. 

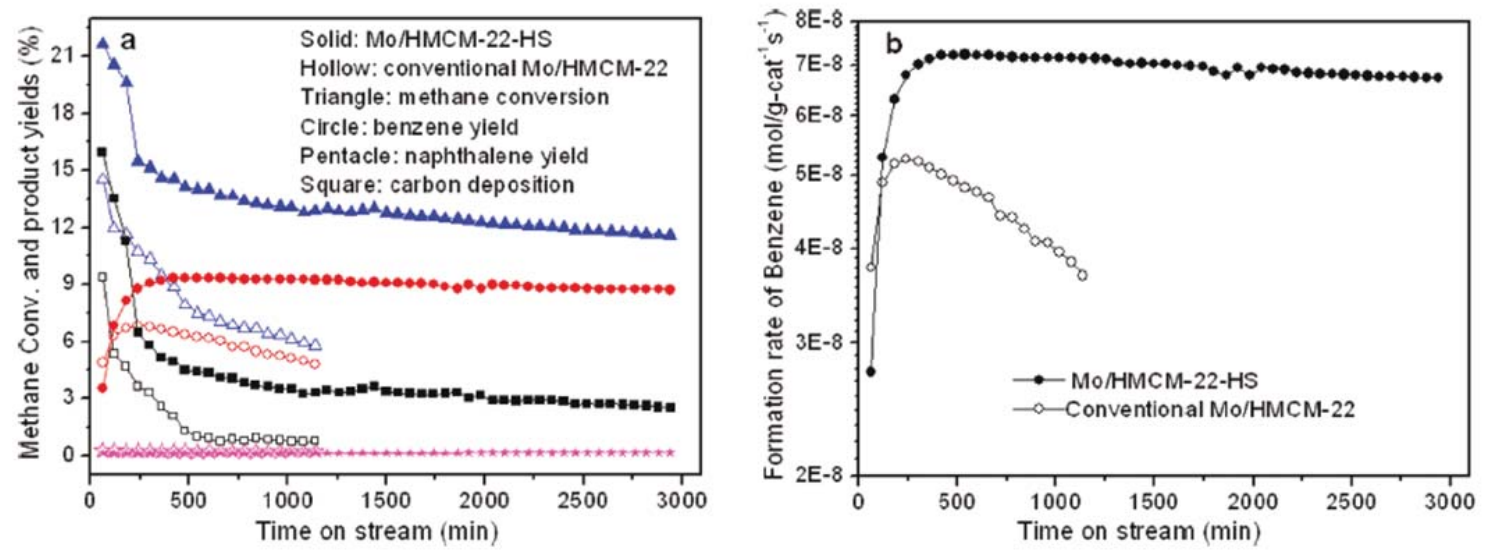

Fig. 3. (a) Catalytic performances of Mo/HMCM-22-HS and conventional Mo/HMCM-22 catalysts for MDA reaction; (b) formation rates of benzene at $973 \mathrm{~K}$ on these two catalysts under space velocity of $1500 \mathrm{ml} /(\mathrm{g} \cdot \mathrm{h})[46]$.

have been synthesized [35].

Micron-sized carbons have also been used as hard templates for the formation of hollow hierarchical zeolites [46-50]. Chu et al. [46] reported the synthesis of hollow hierarchical Mo-MCM-22-HS microspheres by a facile one-pot hydrothermal method involving self-assembly combined with hydrothermal synthesis with carbon black spheres as the core template (Fig. 3). The resultant hollow hierarchical zeolites showed superior catalytic activity for the methane dehydroaromatization reaction (MDA, Fig. 3(a)). The mesopores conferred a higher external surface and the hollow structure offered an important effect on improving the high benzene yield and catalyst lifetime (Fig. 3 (b)). Tang et al. [48,50] used carbon fibres as hard templates to fabricate hollow zeolite fibres through a layer-by-layer adsorption method.

It has been discussed that ordered mesoporous zeolites can be synthesized when the walls are thick enough. Although carbon aerogels (CAs) present disordered structures and heterogeneous pore distributions, their large mesopores and thick mesoporous walls offer a possibility to accommodate stable zeolite nanocrystals. Many efforts have proved that CAs are more suitable candidates as mesoscale templates in the creation of mesoporosity within zeolite crystals in comparison with CMKs templates. For example, Tao et al. [53,54] reported the synthesis of zeolite ZSM-5 monolith and zeolite Y which presented a bimodal pore structure of uniform mesopores via a templating method using a carbon aerogel of uniform mesoporosity. In addition, organic aerogels have also been used as mesoporous templates for the formation of mesoporous zeolitic catalysts [55-58]. Tang and Zhang et al. [57] developed a polymerization-induced colloid aggregation method (PICA) to fabricate various types of dispersed nanozeolite microspheres with large secondary pore architecture. In this work, the polymers formed by the polymerization of urea-formaldehyde were used as the hard templates. The obtained nanozeolite microspheres featured a uniform spherical morphology and a large and adjustable secondary pore architecture. Recently, they have improved this PICA method and reported a polymerization-velocity-match (PVM) method to prepare zeolite microspheres with a hierarchical porous structure and a uniform size
[58]. This improved procedure successfully avoided repeated ultrasonic washing and high-speed centrifugation of the nanozeolite colloid during the traditional PICA method. Of note is that the resultant catalysts showed high catalytic activity and better selectivity for the dehydration of fructose into 5-HMF.

Zeolites with a macroporous structure are another popular and important member of the hierarchically porous zeolite family, which present shorter diffusion path lengths hence faster mass transfer. A macroporous structure with the pore sizes is larger than $50 \mathrm{~nm}$ in zeolitic materials is believed to greatly increase resistance to coke deposition compared to mesoporosity. The use of dispersed polystyrene (PS) microspheres as a hard template is a facile way to create a macroporous system within zeolitic materials [59-70]. Various hollow spheres of zeolitic materials have been fabricated using PS microspheres as hard templates [59-63]. The success of this process largely depends on the homogeneous deposition of nanozeolite particles on PS latex templates. Consequently, it is better to modify the PS microspheres to form a uniform charge layer by the deposition of several layers of poly-electrolytes in order to enhance the adhesion between the zeolite building blocks and the PS spheres through electrostatic interaction. Wang et al. [59] have fabricated various hollow spheres of zeolites through a layer-by-layer technique using PS microspheres as templates and nanozeolites as building blocks. Valtchev et al. $[60,62]$ reported the preparation of hollow zeolite microbeads and films using PS microspheres as hard templates by employing a layer-by-layer self-assembly technique. Furthermore, the uniform PS microspheres templates can easily form an ordered 3-dimensional (3D) macro-structure latex by a self-assembly process. Therefore, zeolite monoliths with a 3D macroporous structure are also the main products when using PS microspheres as macroscale templates [64-70]. For example, Holland et al. [64] demonstrated the preparation of macroporous silicalite- 1 by combining a PS sphere templating technique with the use of an appropriate structure directing agent. Zhu et al. [67] reported in detail on the preparation of highly-ordered 3D macro-micro bifunctionally porous materials using zeolite LTA, FAU, LTL, BEA, and MFI nanocrystals as building blocks and PS microspheres as hard templates. Moreover, Zhou and Antoniet- 
ti [69] developed a novel hierarchical 3D ordered bimodal porous framework with significant increased mechanical stability, by simultaneously using three-dimensionally ordered PS patterns and an amphiphilic ionic liquid as templates combining a secondary hydrothermal treatment.

Furthermore, mesoporous silica (MS) spheres have also been used as sacrificial templates for the formation of hollow zeolites and ordered 3D macroporous zeolites and as digestible template as silica nutrients for the growth of the zeolite building blocks [71-81]. Moreover, another advantage of MS templates is that various active interiors, such as $\mathrm{Fe}_{2} \mathrm{O}_{3}[71,78], \mathrm{Ag}$ [75,78,80,81], PdO [75], and Pt [80] nanoparticles can easily be entrapped inside the hollow zeolite capsules by pre-incorporating the guest species into the mesopores of the MS templates. Tang et al. [71-73,75,76,78,80] made great contributions to the development of hierarchically porous zeolitic materials using MS spheres as hard templates. For example, hollow nanozeolite spheres were prepared through a vapor phase transport (VPT) treatment of the nanozeolite (seeds) coated MS sphere templates [71]. The active interiors, $\mathrm{Fe}_{2} \mathrm{O}_{3}$, which had been pre-incorporated in the mesopores of the MS templates, could be entrapped inside the generated capsule along with the digestion of the silica in the MS core. A highly stable, nanopalladium-entrapped zeolitic microcapsular reactor (Pd@S1) was successfully fabricated by Tang et al. [81] and presented superior catalytic performance for Heck coupling reaction (Fig. 4). The Pd@S1 not only exhibited excellent reactivity at low Pd adoption during the reaction, but could also be reused for more than 10 runs with negligible loss of activity, in contrast to the rapid decay in activity of conventional Pd/C catalysts (Fig. 4(c) and (d)). 3D-ordered macroporous zeolitic macrostructures with closed macropores have also been prepared via the templating effect of MS spheres [75,76]. However, the closed macroporous structure produced in this approach is not favorable for mass transport. Wang and Caruso [82] presented a modified approach to prepare zeolite monoliths with 3D interconnected macroporous structures using MS spheres as templates. Significantly, the zeolitic monolith with 3D interconnected macropores exhibited higher enzyme loadings and activities than the corresponding zeolite monolith with closed macroporous or non-porous structure. In addition, Xiong et al. [74] fabricated zeolite ZSM-5 spheres with a core-shell structure by a combination of pulsed laser deposition (PLD) and vapor-phase crystallization using spherical mesoporous DAM-1 or SBA-15 as the silicon source and substrate.

Moreover, another interesting approach for the preparation of hierarchical meso-/macro-porous zeolites is the use of various solid templates which are cheap and readily available, such as starch-derived bread [83], fly ash cenospheres (FACs) $[84,85]$, cotton threads [86,87], plant cells [88], and some nanosized inorganic templates i.e. $\mathrm{CaCO}_{3} \quad[89,90]$ and $\mathrm{Fe}_{3}\left(\mathrm{SO}_{4}\right)_{2}(\mathrm{OH})_{5} \cdot \mathrm{H}_{2} \mathrm{O}[91]$.

\subsubsection{Soft-templating}

Soft-templating is mainly used to create mesoporous structure within zeolitic materials, which should be attributed to the meso-scaled size of the current available soft templates. In this approach, an organized self-assembly of surfactant molecules or hydrophilic cationic polymers is used to template mesopores within zeolite materials. In all successful examples using soft templating methods to mesoporous zeolites, the use of soft-templates that have strong interactions with silica-based

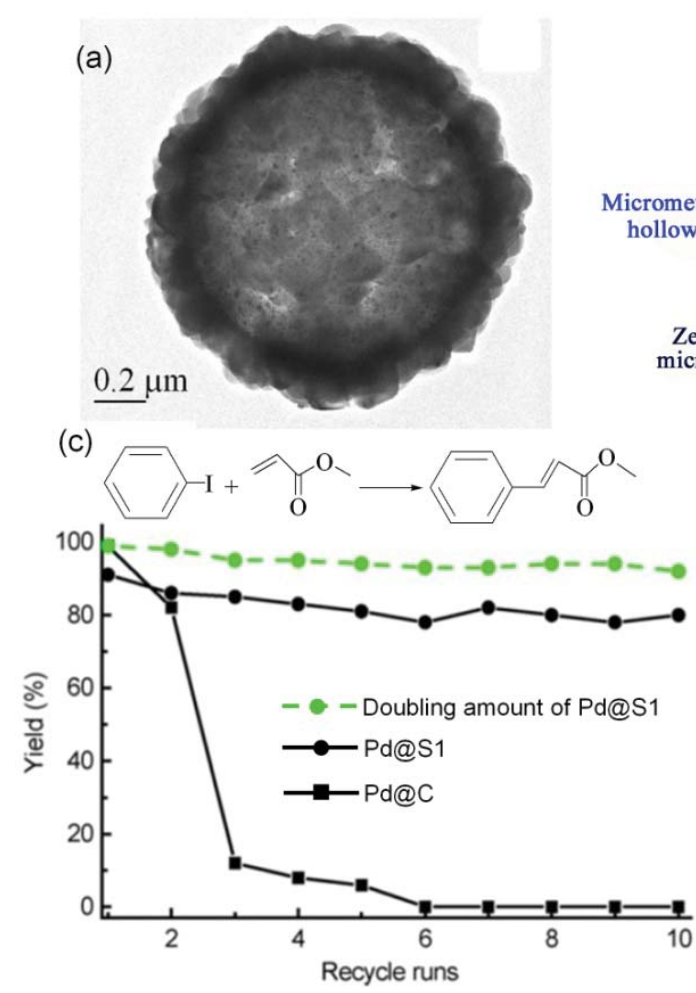

(b)

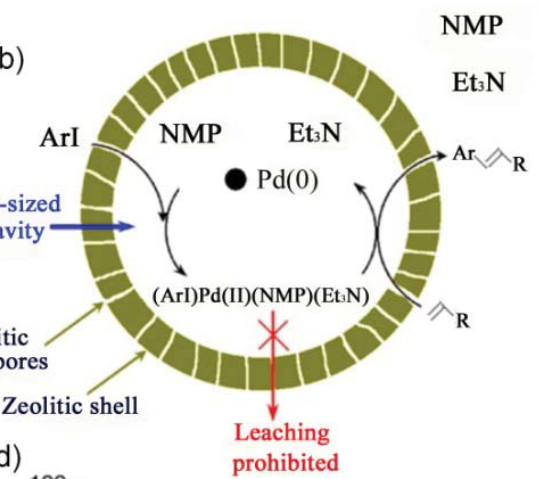

(d)

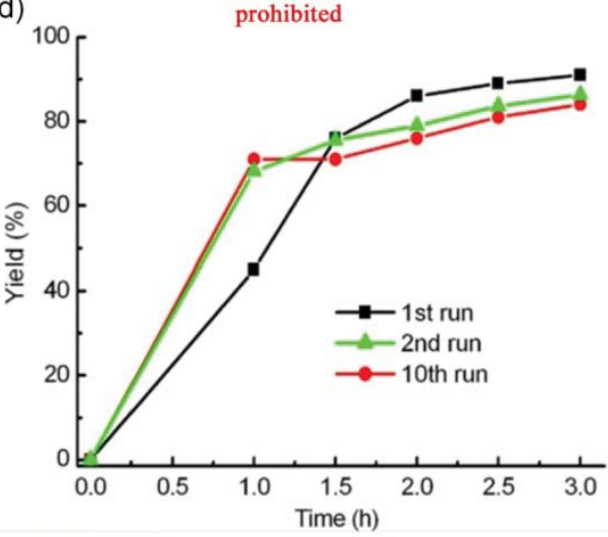

Fig. 4. (a) TEM images of fresh Pd@S1 catalyst. (b) Schematic illustration for the encaged quasi-homogeneous Heck coupling in Pd@S1 catalyst. (c) The Heck coupling activity and reusability of Pd@S1 and Pd/C. (d) Kinetic results of Pd@S1 catalyst in the 1st, 2nd, and 10th runs [81]. 
species has the greatest chance of fabricating mesoporous zeolites, with high stability towards the alkaline synthesis media at the relative high temperatures required for zeolite crystallization. Consequently, the choice of soft-template is of vital importance in creating the mesopores due to the complex factors involved during the zeolite crystallization process.

Inspired by the discovery of mesoporous molecular sieves, zeolite scientists have tried arduously to synthesize ordered mesoporous zeolitic materials using conventional surfactants. However, it has only been partially successful using this approach since disordered mesoporous zeolites have usually been obtained due to the relatively weak interaction between the surfactant and the silica-based species in the synthesis of zeolites [92,93]. Zhao et al. [92] reported a direct fabrication of mesoporous zeolite with a hollow spherical/ellipsoidal capsule structure by using conventional TPAOH and CTAB as soft micro- and mesoporous templates. The resultant mesoporous zeolites presented a mesostructure, high surface area, a relatively small mesopore size of around $3 \mathrm{~nm}$, and a high concentration of strong acidity sites, which contributed to its much higher catalytic activity towards aldol condensations of benzaldehyde than amorphous mesoporous aluminosilicate and conventional ZSM-5, especially when large molecules were involved [92]. To increase the interaction between surfactant and silica-based species, it is necessary to introduce an additive to swell the micelle in the system [94]. However, there is still a big challenge for the formation for hierarchical zeolites with an ordered mesoporous structure using a soft-templating approach. The key factor is to coordinate the interaction between the mesoscale organic templates and the silica-based species during the crystallization phase. For this purpose, organosilanes have been widely used as soft-templates to prepare hierarchical mesoporous zeolites because they can easily interact with silica-based species [95-103]. In this field, Ryoo et al. [95-103] demonstrated a series of successful examples to fabricate mesoporous zeolites using organosilanes as soft-templates. They developed a series of amphiphilic orga- nosilanes with a positive charge as the mesopore-directing agents in the synthesis of mesoporous zeolites. These designed amphiphilic organosilanes $\left(\left[\left(\mathrm{CH}_{3} \mathrm{O}\right)_{3} \mathrm{SiC}_{3} \mathrm{H}_{6} \mathrm{~N}\left(\mathrm{CH}_{3}\right)_{2} \mathrm{C}_{n} \mathrm{H}_{2 n+1}\right] \mathrm{Cl}\right)$ constructed from a hydrolysable methoxysilyl moiety, a zeolite structure-directing group such as quaternary ammonium, and a long-chain hydrophobic alkyl group [95-99]. The templates could strongly interact with growing crystal domains through the formation of covalent bonds with other $\mathrm{SiO}_{2}$ and $\mathrm{Al}_{2} \mathrm{O}_{3}$ sources using the methoxysilyl moiety in order to fabricate mesoporous MFI zeolites [95]. Several attractive features such as large surface areas, interconnected mesopores with zeolitic pore walls, pore size control, facile synthesis on a large scale and so on could be achieved by this approach. On the basis of this approach, a series of hierarchical mesoporous zeolites including aluminosilicate and aluminophosphate zeolites have been successfully obtained [96-99]. Furthermore, Ryoo et al. [95-99] have carefully investigated the catalytic properties of these mesoporous zeolites in comparison with the conventional zeolites. The resultant mesoporous MFI zeolite and ZSM-5 had similar activities in the transformation of methanol to olefin/gasoline. In contrast, for catalytic reactions involving large organic molecules, the mesoporous MFI zeolites exhibited much higher catalytic activities and selectivities in the synthesis of jasminaldehyde (98\%) and vesidryl (60\%, Table 1). Significantly, these zeolites, with mesoporous/microporous hierarchical structure, showed remarkably high catalytic activities and high resistance to deactivation in various reactions such as the isomerization of 1,2,4-trimethylbenzene, cumene cracking, esterification of benzyl alcohol with hexanoic acid, Knoevenagel condensation, Claisen-Schmidt condensation in liquid phase, acetonylacetone cyclization in vapor phase and conversion of methanol to dimethyl ether and hydrocarbons [96-99]. Later, Choi et al [101,102] approached the synthesis of MFI nanosheets by using a di-quaternary ammonium-type surfactant $\left(\mathrm{C}_{22-6-6}\right)$ which was composed of a long-chain alkyl group $\left(\mathrm{C}_{22}\right)$ and two quaternary ammonium groups spaced by a $\mathrm{C}_{6}$ alkyl linkage. With this surfactant, an ultrathin zeolite frame-

\section{Table 1}

Catalytic properties of mesoporous MFI zeolite and other aluminosilicate materials [95].

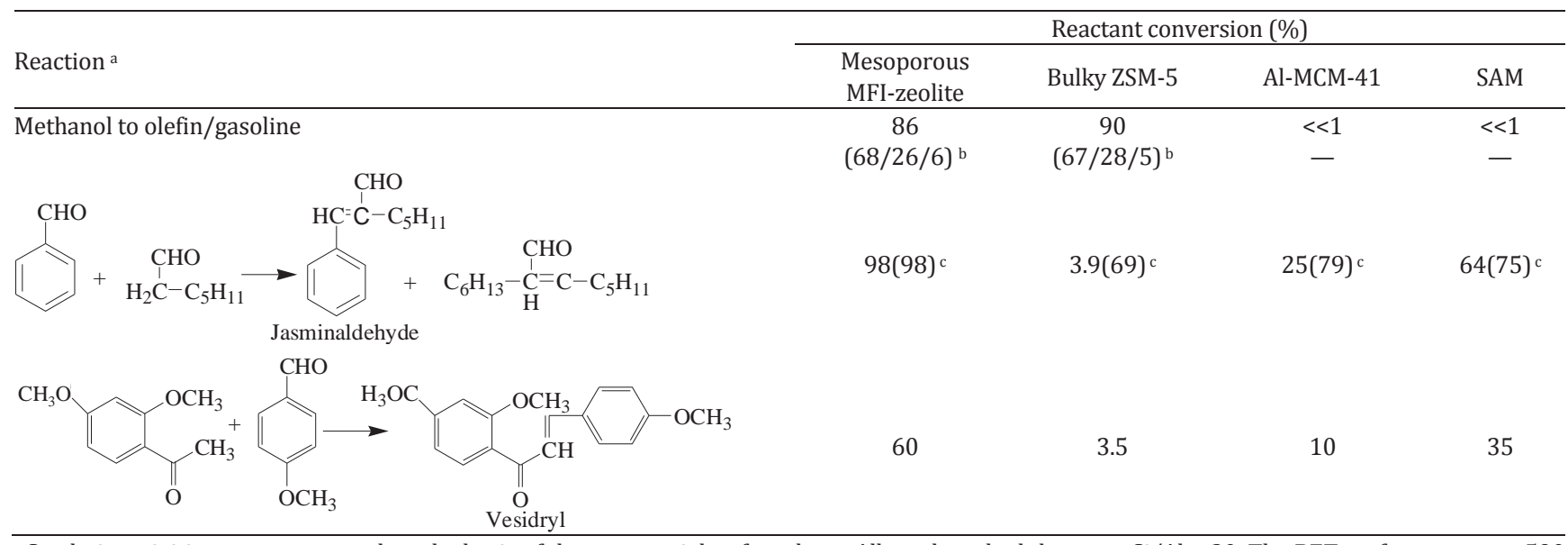

${ }^{a}$ Catalytic activities were compared on the basis of the same weight of catalysts. All catalysts had the same $\mathrm{Si} / \mathrm{Al}=20$. The BET surface area was 590 $\mathrm{m}^{2} / \mathrm{g}$ for mesoporous MFI, $350 \mathrm{~m}^{2} / \mathrm{g}$ for ZSM-5, $948 \mathrm{~m}^{2} / \mathrm{g}$ for AlMCM-41, and $923 \mathrm{~m}^{2} / \mathrm{g}$ for SAM (MCM-41-type).

bSelectivity (\%) for olefin/gasoline/others.

cSelectivity (\%) for jasminaldehyde. 
work was formed at the hydrophilic part of the micelles while the hydrophobic tail restricted the excessive growth of zeolites. Of note is that ordinary surfactants, with a single quaternary ammonium group, failed to function as an effective structure-directing agent for zeolite formation [101]. These MFI nanosheets presented superior catalytic performances in organic reactions involving large organic molecules. Wang et al. [100] reported another successful example of the organosilane templating method, which used silylated polyethyleneimine polymers as a porogen in the formation of intracrystal mesopores within a zeolite matrix. The presence of $-\mathrm{SiO}_{3}$ units in the polymer allowed it to be integrated into a silica-alumina sol-gel reaction mixture and nucleation of the zeolite phase in the presence of the silylated polymer was accompanied by the grafting of the polymer to the zeolite surface through covalent Si-O-Si linkages. As the zeolite crystal grew, the incorporated polymer became phase-segregated from the zeolite matrix, forming an intracrystal polymer network that was covalently linked to the zeolite framework [100]. Very recently, significant progress has been achieved by Ryoo's group, who have creatively synthesized a hexagonally ordered mesoporous molecular sieve (MMS) with a $1.7 \mathrm{~nm}$ thick crystalline MFI-like microporous framework using a surfactant composed of three quaternary ammoniums (18-N3-18, Fig. 5) [103]. The mesopores were generated by surfactant aggregates, whereas crystalline microporous zeolite frameworks were generated by multiple quaternary ammonium groups. In this work, the wall thickness and framework topology could be adjusted by using surfactants with different geminilike head groups. Further- more, mesopores with a narrow pore size distribution could be tailored according to the surfactant tail length or by the addition of hydrophobic swelling agents. The crystalline MMSs exhibited much higher catalytic performances than both bulk Beta zeolite and Al-MCM-41for various organic reactions involving bulky molecules (Table 2), which might be attributed to the facile diffusion through the MMS mesopores, strong acidities of their crystalline zeolitic framework, and high concentrations of surface acid sites that were accessible to organic substrates.

Beside, hydrophilic cationic polymers have proved to be suitable mesoporous templates for use in the synthesis of various zeolite structures, not only because they can strongly interact with silica-based species due to their high positive charge-density but also that these templates present very high stabilities under high temperature alkaline conditions. A series of hierarchical zeolitic mesoporous materials prepared using cationic polymers as mesoporous templates have been reported by Xiao et al. [104-107]. They demonstrated a facile and universal route for the synthesis of hierarchical mesoporous Beta zeolite (Beta-H) templated from a mixture of microporous structure directing agents and a mesoscale cationic polymer, poly diallyldimethylammonium chloride (PDADMAC) by a one-step hydrothermal synthesis [104]. The resultant hierarchically mesoporous Beta-H showed a high activity and selectivity as a catalyst for the alkylation of benzene with propan-2-ol, as well as a long lifetime relative to conventional Beta zeolite (Fig. 6). Later, hierarchically mesoporous ZSM-5 and $\mathrm{NaX}$ were obtained using this confined cationic polymer tem-

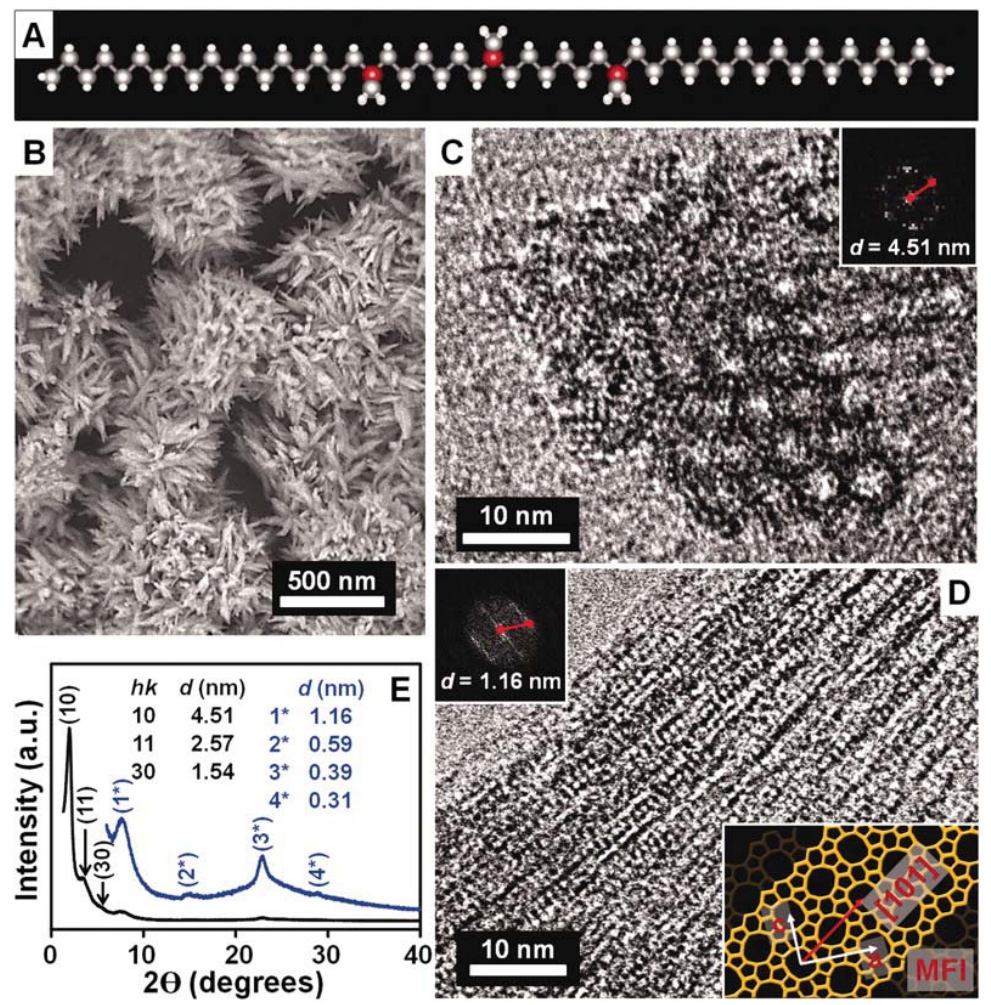

Fig. 5. (A) Molecular model of 18-N3-18 surfactant. (B) SEM image. (C and D) TEM image [(C) and (D) insets, Fourier diffractogram]. (E) XRD pattern of hexagonally ordered crystalline MMS after surfactant removal. For structural comparison, an MFI framework model is given in the bottom right inset of (D). $h k$, Miller indices; a.u., arbitrary units [103]. 
Table 2

Comparison of catalytic conversions over different porous aluminosilicates [103].

\begin{tabular}{|c|c|c|c|c|}
\hline \multirow[b]{2}{*}{ Reaction $^{a}$} & \multicolumn{4}{|c|}{ Reactant conversion (\%) } \\
\hline & $\begin{array}{c}\text { Hexagonal } \\
\mathrm{MMS}^{\mathrm{b}}(\mathrm{Si} / \mathrm{Al}=15)\end{array}$ & $\begin{array}{c}\mathrm{N}_{6} \text {-diphe betac } \\
(\mathrm{Si} / \mathrm{Al}=14)\end{array}$ & $\begin{array}{c}\text { Bulk beta } \\
(\mathrm{Si} / \mathrm{Al}=15)\end{array}$ & $\begin{array}{l}\text { Al-MCM-41 } \\
(\mathrm{Si} / \mathrm{Al}=17)\end{array}$ \\
\hline & $44(71)^{d}$ & $33(68)^{d}$ & $19(56)^{d}$ & $8(86)^{d}$ \\
\hline & 82 & 59 & $<5$ & $<5$ \\
\hline & $52(>95)^{\mathrm{e}}$ & $65(>95)^{e}$ & $<5(>95)^{\mathrm{e}}$ & $<5(>95)^{\mathrm{e}}$ \\
\hline & $72(68)^{f}$ & $61(93)^{\mathrm{f}}$ & $20(26)^{f}$ & $<5(95)^{\mathrm{f}}$ \\
\hline
\end{tabular}

a Catalytic activities are compared on the basis of the same weight of catalyst.

${ }^{\mathrm{b}}$ Hexagonally ordered crystalline MMS synthesized by using the 18-N3-18 surfactant.

${ }^{\mathrm{c}}$ Crystalline MMS built with zeolite beta framework synthesized by using N6-diphe surfactant.

d Selectivity (\%) for diphenylmethane.

e Selectivity (\%) for 4-benzoyl-1-methoxynaphthalene.

f Selectivity (\%) for vitamin E (a-tocopherol).

plating method $[105,106]$. These samples presented a disordered hierarchy of mesopores with a broad pore size distribution and ordered micropores. Recently, stable and bulky Beta zeolite particles with high external surface area and large pore volume were fabricated from the self-assembly of Beta nanocrystals with cationic polymers (PDADMAC) under hydrothermal conditions [107]. Very recently, they presented a successful example that appropriately designed amphiphilic copolymers with high molecular weight can direct the formation of zeolite ZSM-5 single crystals with $b$-axis-aligned mesopores (ZSM-5-OM) [108]. They used copolymer polystyrene-co-4-polyvinylpyridine $\left(M_{\mathrm{W}} \approx 1.6 \times 10^{5}\right.$, PSt-co-P4VP) which was treated with methyl iodide, forming a cationic polymer (C-PSt-co-P4VP). The positively charged C-PSt-co-P4VP strengthens its interaction with the negatively charged silica

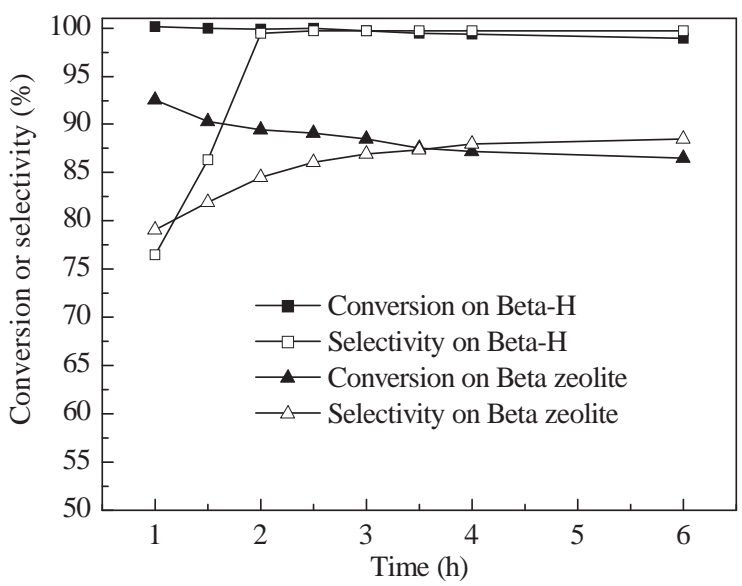

Fig. 6. Catalytic conversionsand selectivities in the alkylation of benzene with propan-2-ol with various zeolites samples as a function of reaction time [104]. Reaction conditions: $200{ }^{\circ} \mathrm{C}$, benzene/propan-2-ol ratio 4:1, $2.0 \mathrm{MP}, \mathrm{WHSV}=10 \mathrm{~h}^{-1}$. species in the synthesis of zeolites and is thus a favorable template for synthesizing zeolites with oriented mesopores. The resultant catalysts exhibited excellent hydrothermal stability and superior catalytic activities for conversion of bulky substrates. In addition, Zhu et al. [109] reported the synthesis of hierarchically mesoporous Beta and ZSM-11 templated by polyvinyl butyral (PVB) gel as the mesopore directing agent. The resultant hierarchical mesoporous zeolites exhibited higher conversion rates and enhanced resistance toward deactivation in the cracking of 1,3,5-trimethylbenzene and 1,2,4-trimethybenzene in comparison with conventional zeolites. It is worth noting that the great variety of available low cost cationic polymers yields the possibility to produce a wide range of commercially interesting hierarchically mesoporous zeolites on an industrial scale.

\subsubsection{Post-treatment}

Currently, post-treatment methods are the main industrial strategies employed to synthesize hierarchically mesostructured zeolites [110,111]. There are two main approaches: dealumination and desilication. Dealumination is a conventional method, initially used to increase the acid strength of zeolites, that involves the leaching of tetrahedrally coordinated aluminum from the zeolite framework to form intracrystalline mesoporosity $[112,113]$. This process can be achieved by steam treatment at high temperatures, or by acid leaching using nitric or hydrochloric acid [114-118]. However the dealumination is often developed at the expense of zeolite crystallinity, which consequently leads to a reduction in catalytic activity [113]. Therefore, dealumination is not used to create intracrystalline mesopores in zeolites. In contrast, desilication of a zeolite framework by treatment in aqueous alkaline solution has proven to be a more efficient method to introduce intracrystal- 
line mesopores into the zeolite crystals [119-129]. Ogura [31] investigated the catalytic performances of as-synthesized zeolite ZSM-5 and alkali-treated ZSM-5. The result clarifies that the catalytic performance of ZSM-5 was enhanced by alkali treatment, with more than a 1.5 times higher conversion for the same contact time being achieved. They claimed that alkali post-treatment does not lead to stronger acidity but leads to a greater degree of diffusivity inside the zeolite crystal, providing easier access to the microporous entrance via the mesopores created by the treatment [31,119]. Groen et al. [121] investigated the role of concentration and the nature of aluminium in the creation of hierarchical porosity in both commercial and synthesized MFI zeolites through the development of a controlled mesoporosity by desilication in alkaline medium. The influence of the Si/Al ratio on the desilication treatment of MFI zeolites in $\mathrm{NaOH}$ solution and the associated mechanism of pre-formation has been studied. They found that framework aluminium controls the process of framework silicon extraction and makes desilication selective towards intracrystalline mesopore formation. The results revealed that the optimal molar $\mathrm{Si} / \mathrm{Al}$ ratio is in the range $25-50$, this leads to an optimal mesoporosity centred around $10 \mathrm{~nm}$ and mesopore surface areas of up to $235 \mathrm{~m}^{2} / \mathrm{g}$ while preserving the intrinsic crystalline and acidic properties. At lower framework $\mathrm{Si} / \mathrm{Al}$ ratios the relatively high $\mathrm{Al}$ content inhibits Si extraction and hardly any mesopores are created, while in highly siliceous ZSM-5 unselective extraction of framework Si induces formation of large pores. Recently, an alkali-treated desilication method has also been used to synthesize zeolite microboxes with large hollow cores $[130,131]$. Mei et al. [130] reported the synthesis of HZSM-5 zeolite microboxes with a thin intact shell and large hollow core by a mild alkaline treatment of ZSM-5 single-crystals with $\mathrm{NaCO}_{3}$ solution (Fig. 7(a) and (b)). It is worth noting that the intrinsic crystalline properties in the alkaline treated zeolite are well preserved. The zeolite microbox catalysts show superior catalytic activities for gas-phase cumene cracking and liquid-phase $\alpha$-pinene isomerization compared with parent HZSM-5 (Fig. 7(c) and (d)). On the basis of this mild alkaline treatment method, Wang and Tuel [131] developed a pseudomorphic transformation process to synthesize ZSM-5 nanoboxes with very regular pore geometry and wall thickness. The pseudomorphic transformation involves the preferential dissolution of crystal cores, followed by local re-crystallization of species in the presence of aluminum and templating molecules.

\subsubsection{Hierarchically porous scaffolds}

Recently, hierarchically porous zeolitic materials prepared by using a hierarchically porous scaffold have commanded much interest. Various supports with macropores or hierarchical meso-macropores were used to prepare micro-macroporous or micro-meso-macroporous hierarchical porous zeolitic materials. Most successful examples mainly focus on the formation of hierarchical micro-macroporous zeolitic materials by the hierarchically porous scaffold. In practice, these macroporous scaffolds can be serviced both as macroporous supports and the initial nutrients for the growth of a zeolite microporous framework. Currently, many inorganic macroporous supports have been successfully employed to fabricate hierarchical porous zeolitic materials, such as porous $\alpha-\mathrm{Al}_{2} \mathrm{O}_{3}$ [132], stainless steel [133], cordierite honeycomb [134,135], $\mathrm{SiC} / \mathrm{Al}_{2} \mathrm{O}_{3}$ [136], $\mathrm{ZrO}_{2} / \mathrm{Y}_{2} \mathrm{O}_{3}$ [136], microcellular ceramic foams [137,138], diatom [139], and $\mathrm{ZrO}_{2}$ [140]. These macroporous supports were used only as a robust support. The zeolite monolith on the macroporous support was generally obtained using a conventional one-step hydrothermal crystallization by immersing the supports into a precursor solution of a typical zeolite synthesis and then the zeolite crystals were loaded or coated onto the surface of the macroporous supports that provided the required macroporosity. For example, Zampieri et al. [137] reported the synthesis of a novel zeolite-ceramic composite material obtained by coating the cell walls of microcellular polymer-derived ceramic foams with a thin, binder-free layer of MFI-type zeolite (silicalite-1 and ZSM-5) via an in-situ conventional hydrothermal synthesis in the presence of these foam supports. The resultant composite possessed a bimodal pore system, a high thermal stability (more than $600{ }^{\circ} \mathrm{C}$ in air) and good mechanical strength, which would be well suited for the development of a structured monolithic microreactor. Wang et al. [139] demonstrated the fabrication of hierarchically structured zeolites through a layer-by-layer assembly of zeolite nanocrystals on diatom supports. Furthermore, many sacrificial supports have also been applied to the fabrication of hierarchically micro-macroporous structured zeolitic materials, such as swollen bacterial super cellular threads [141], starch gels [142], polyurethane foams [143], wood cell [144], cellulose acetate [145], luffa sponge
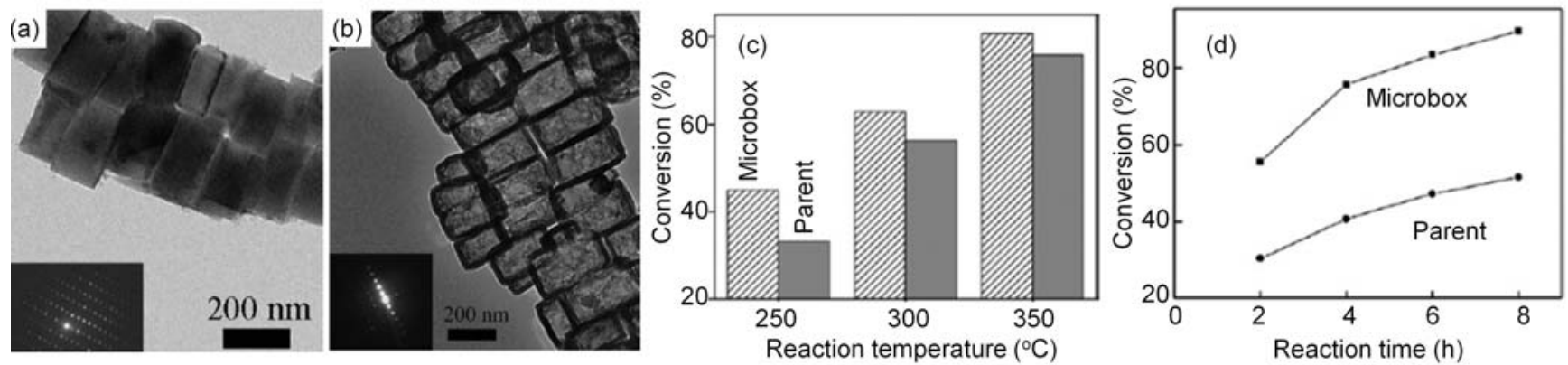

Fig. 7. TEM image and electron diffraction (ED) pattern of the used single-crystal parent HZSM-5 (a) and the HZSM-5 microboxes (b); Conversion of cumene cracking at 250,300 , and $350^{\circ} \mathrm{C}$ over a HZSM-5 microbox catalyst and parent single-crystalline zeolite (c); Conversion of $\alpha$-pinene isomerization as a function of reaction time at $150^{\circ} \mathrm{C}$ over a HZSM- 5 microbox catalyst and parent HZSM-5 (d) [130]. 
[146], and egg-derived scaffolds [147]. For example, hierarchically structured zeolite fibers containing ordered pores at the nano- and micro-scopic length scale were prepared from the infiltration of swollen bacterial super cellular threads with as-synthesized silicalite nanoparticles [141]. Lei et al. [143] used polyurethane foams as a template to construct large monolithic silicalite-1 and ZSM-5 foams, having highly ramified networks of interconnecting macropores with tailorable sizes and shapes. Dong et al. [144] demonstrated a general and facile route involving a seeded growth strategy for the conversion of cedar and bamboo woods into hierarchically porous zeolitic materials. Furthermore, biomorphic MFI-type zeolite frameworks with hierarchical porosity and complex architecture were prepared by employing a macroscale sacrificial structural scaffold (a biological template-luffa sponge) via an in-situ seeding and secondary crystal growth hydrothermal synthesis [146]. Recently, a micro-macroporous interwoven hollow tube was prepared by the secondary growth of pre-adsorbed ZSM-5 zeolite on eggshell membranes [147]. However, these hierarchical micro-macroporous zeolitic materials prepared from robust macroporous supports generally possessed low mechanical strength and low acidity due to the low zeolite loading and the weak binding capacity between the zeolite nanocrystals and the surface of the supports, which seriously limited their practical applications. To overcome this obstacle, Wang et al. [140] used a considerably modified macroporous supports, a polyelectrolyte-coated, 3D ordered, macroporous activated zirconia, to fabricate $3 \mathrm{D}$ ordered macroporous $\mathrm{ZrO}_{2}$-zeolite composites with a high stability (Fig. 8).

Another solution to improve the mechanical stability of the resultant hierarchically porous zeolitic material via the use of a hierarchically porous scaffold is to use supports which not only serve as a macroporous scaffold but also as the initial nutrients. Generally, these supports should contain active silica or alumina, which can be completely or partially crystallized during the formation of the micro-macroporos structures. Hierarchically
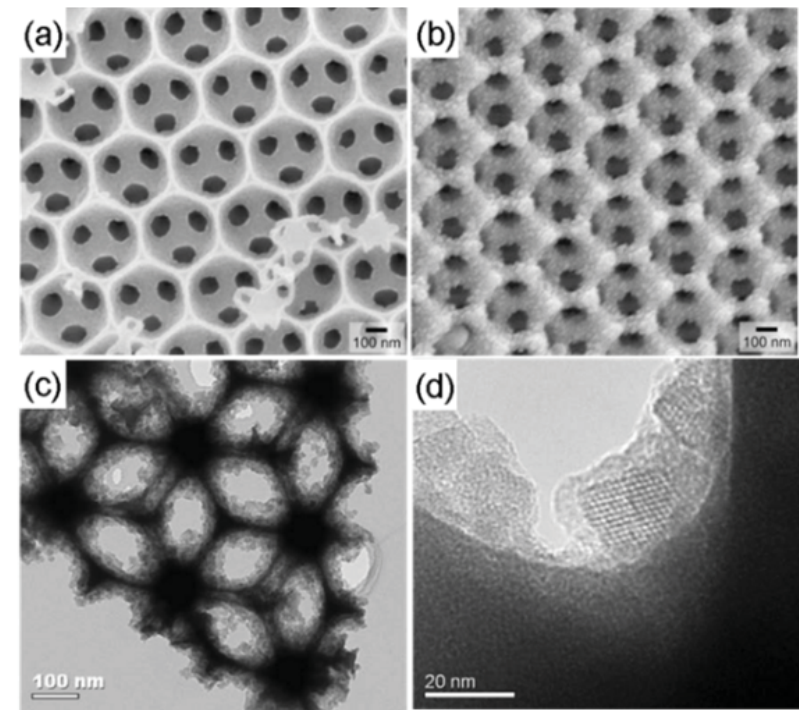

Fig. 8. SEM images of 3DOM SZ (a) and 3DOM SZ/NaY(b), TEM image of 3DOM SZ/NaY (c), and a high-resolution TEM image of 3DOM SZ/NaY (d) [140]. porous zeolitic materials made in this way show high mechanical stability owing to a strong interaction between zeolite nanocrystals or zeolite coatings and the supports employed. These supports include sintered kaolin honeycomb [148], diatoms $[149,150]$, biomorphic rattan-derived cellular SiSiC ceramics [151,152], pumice granules [153], porous glass [154$158]$, and hierarchically meso-macroporous silica or aluminosilicates [159-170]. For example, Komarneni et al. [148] developed a novel honeycomb composite structure consisting of microporous ZSM- 5 and macroporous mullite by in-situ crystallization of ZSM-5 utilizing glass from a sintered kaolin honeycomb. Significantly, this in-situ crystallization of ZSM-5 resulted in better adhesion and mechanical strength for the resultant zeolite film. Anderson et al. [149] reported the synthesis of a stable micro/macroporous composite material by the zeolitization of diatomaceous earth. Wang et al. [150] demonstrated a simple approach to the preparation of hierarchically structured zeolites by transforming diatomaceous silica into zeolite by a vapor-phase transport (VPT) method. Zampieri et al. [151,152] prepared bio-inspired structured SiSiC-zeolite composites using biomorphic rattan-derived cellular SiSiC ceramics as supports via biotemplating liquid silicon infiltration (LSI) and zeolite crystallization transformation processes. In addition, cheap, abundant macroporous pumice granules have also been used to prepare micro-macroporous hierarchical materials through the zeolitization of superstructured pumice by Johnson and Worrall [153]. In all these examples, the supports have only been partly crystallized and still serviced as a macroporous scaffold. Moreover, binder-free zeolitic materials with hierarchical micro-macroporous structures prepared by a complete crystallization of a macroporous support have also recently attracted much attention. For example, Dong et al. $[154,155]$ synthesized pure phases of B-Al-ZSM-5 and boron-containing TON-type zeolite by self-transformation of porous glass in a vapor phase. Shimizu et al. [156] reported a newly termed dynamic bulk-material dissolution (DBMD) technique to fabricate tube-shaped zeolites by converting bulk glass materials to zeolites and replacing the glassy part by zeolitic crystals. Furthermore, the macroporous glass beads were also used as supports and transformed into MFI-type containing beads that retained the original shape [157].

In most of these previous studies, hierarchically porous zeolitic materials with either mesopores or macropores were designed and synthesized. Today, to introduce both mesopores and macropores into zeolitic materials is still a big challenge. However, zeolitic materials with both mesopores and macropores are much more desirable. Currently, a complete zeolitization of hierarchical meso-macroporous supports is the main strategy to synthesize hierarchical zeolitic materials with a meso-macroporous structure. For example, Lei et al. [160] fabricated hierarchically structured monolithic silicalite- 1 by transforming the skeleton of the macroporous silica gel via a steam-assisted conversion method. Here, the bimodally porous silica gel served as both a macroporous scaffold and a silica source. Following this strategy, they also synthesized hierarchically meso-macroporous ZSM-5 [161-163] and Beta [143] zeolite monoliths. The resultant hierarchically porous ZSM-5 
zeolites showed high catalytic activity and a long catalyst lifetime for the catalytic cracking of large molecules, such as 1,3,5-triisopropylbenzene (TIPB) [161]. The hierarchical zeolite catalyst exhibited an initially high catalytic activity corresponding to $98 \%$ conversion and even after $3 \mathrm{~h}$ TIPB conversion was still $85 \%$. Of note is that the conversion and product distributions were basically stable when the reaction time was longer than $1.5 \mathrm{~h}$. Özcan et al. [164] reported the hydrothermal synthesis of binderless zeolite A bars and tubes of high purity with moderate mechanical strength and bimodal pore size distribution. Recently, Sachse et al. [163] developed a novel method for the fabrication of zeolite monoliths with a hierarchical pore system by pseudomorphic transformation of a meso-/macroporous silica monolith. The preservation of a crack-free monolith as well as the homogeneous macroporous network accounted for its successful use as a basic catalyst for reactions in a flowing liquid phase. Furthermore, columned ZSM-5 zeolite monoliths with hierarchical mesoporous and macroporous structures and excellent mechanical strength prepared by hydrothermal transformation of the $\beta$ zeolite-containing precursors have been reported by Wang et al. [166]. Yang et al. [167] prepared a novel hierarchical SAPO-34 monolith with a meso-macroporous structure using an amorphous silicoaluminophosphate monolith as a support in a dry gel conversion process. This hierarchical SAPO-34 presented higher catalytic performance than the conventional SAPO-34 in the catalytic conversion of methanol to light olefins.

Evidently, the introduction of large pores within zeolitic materials plays a key factor to enhance mass transport property, which results in an improvement of catalytic performance. Moreover, mesopores with uniform pore size distribution should be targeted as they can be beneficial in improving the selectivity of a catalyst. More importantly, on all length scales, the connectivity between the various levels of pores is vital to maximize the benefits of hierarchy of catalysts in catalytic reactions. Consequently, the design of hierarchical zeolites should be aimed not only at extensively introducing larger pores, but principally by locating them such that they interconnect with the micropores. To achieve this purpose, a novel quasi-solid-state crystallizaition approach has been successfully employed to fabricate hierarchically porous zeolites with micro-meso-macroporous structures by Chen at al. [12,15,168-
170]. The pores were on three length scales and incorporated in one solid body were interconnected with each other. Figure 9 illustrates the general synthesis procedure of hierarchically micro-meso-macroporous zeolites by a quasi-solid-state crystallization process [168]. Meso-macroporous aluminosilicates synthesized by a spontaneous self-formation process were used as scaffold templates, as well as the silica and alumina source [12-14]. These amorphous meso-macroporous aluminosilicates precursors could be transformed into microporous zeolite nanocrystals with the effect of a zeolite structure-directing agent in a glycerin medium. During the transformation, the macroporosity was not affected and thus entirely transferred to the final materials constructed from nanocrystals. The key factor is probably the use of a glycerin medium instead of more conventional hydrothermal conditions as it might ensure that the crystallization process is conducted without the collapse of the hierarchical meso-macroporous structure [15]. The resultant materials possessed hierarchical porous systems on three length scales: a well-defined macroporous structure with highly interconnected mesopores, which developed during the growth of the microporous zeolite nanocrystals on the basis of the mesoporosity of the precursors, and micropores which could be tailored by controlling the zeolite type [168-170]. Significantly, these hierarchical micro-meso-macroporous zeolites not only have stable catalytically active sites due to the microporous zeolites, but also bulky molecules can easily diffuse into the macropores and mesopores and make contact with these active sites [170]. By this novel method, a series of hierarchical micro-mesomacroporous catalysts with different zeolite architectures have been obtained [168-170]. Notably, the resultant materials presented a macroscopic network with relatively homogeneous and straight channel-shaped macropores, which were arranged parallel to each other. It can be found that the macropore walls were constructed entirely from uniform zeolite nanocrystals with high crystallinity, resulting in relatively uniform mesopores or mesovoids in the products. For example, the micro-meso-macroporous material MMM(2) obtained after two days crystallization presented a higher catalytic performance than conventional ZSM-5 zeolite for cracking reactions, especially for the cracking of large molecules (see Table 3). This might be attributed to the enhanced accessibility due to the

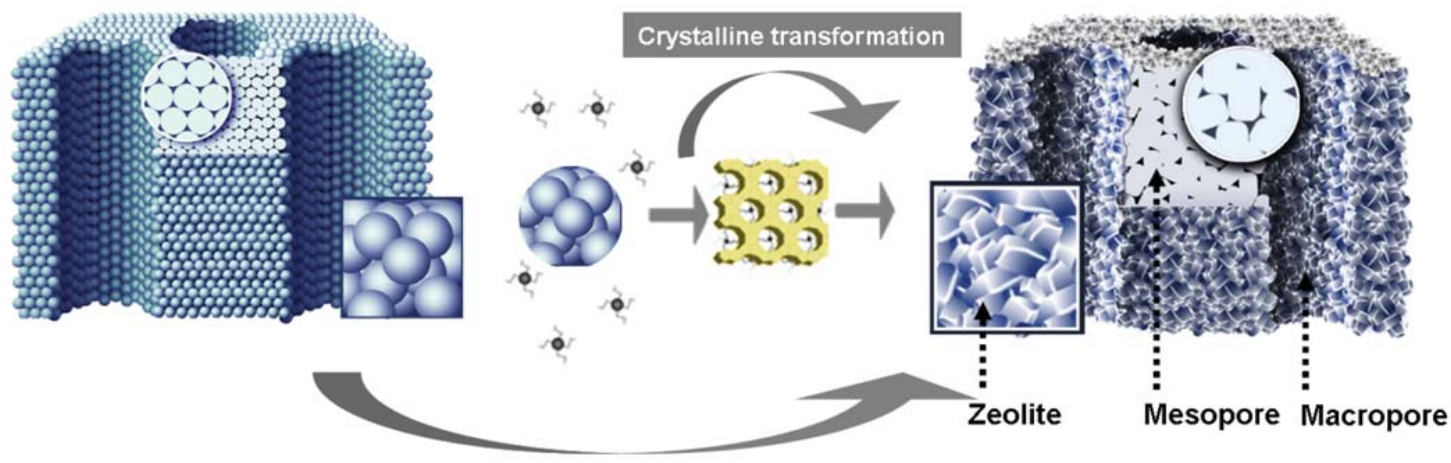

Fig. 9. Schematic representation of the synthesis of hierarchically micro-meso-macroporous aluminosilicates constructed from zeolite nanocrystals by a quasi-solid-state crystallization process [168]. 
Table 3

Catalytic activity for cracking of 1,3,5-triisopropylbenzene and the structural parameters obtained through BET measurements for various samples [168].

\begin{tabular}{lcccc}
\hline Sample & $\begin{array}{c}\text { Conversion } \\
(\%)\end{array}$ & $\begin{array}{c}\text { Contact time } \\
(\mathrm{ms})\end{array}$ & $\begin{array}{c}\text { BET surface } \\
\text { area }\left(\mathrm{m}^{2} / \mathrm{g}\right)\end{array}$ & Si/Al ratio \\
\hline MMM(2) & 28.59 & 12 & 562 & 80 \\
& 44.46 & 18 & & \\
& 88.63 & 24 & & \\
ZSM-5 & 17.25 & 12 & 302 & 75 \\
& 23.26 & 18 & & \\
Al-MCM-41 & 23.97 & 24 & & \\
MCM-41 & - & 24 & 996 & 82 \\
\hline
\end{tabular}

hierarchical micro-meso-macroporous structure and strong acidity. The test found that HZSM-5, a commercial catalyst, was much less active (23.97\%) for the cracking of 1,3,5-triisopropylbenzene (TIPB) with a contact time of $24 \mathrm{~ms}$. In contrast, calcined $\operatorname{MMM}(2)$ with the same time yielded the highest activity and could convert $88.63 \%$ TIPB molecules. More importantly, the increase in contact time favored deep cracking of the TIPB reactant, as well as the IPB and DIPB intermediates formed during the reaction, to obtain propylene and benzene. This phenomenon was not observed when using conventional HZSM-5 catalysts. Moreover, hierarchical micro-meso-macroporous Beta zeolite (MMM-Beta) prepared via a similar strategy also exhibited superior catalytic activity and selectivity for the esterification of benzyl alcohol with hexanoic acid [169]. It is worth noting that the conversion rate using MMM-Beta could reach $92 \%$, which was much higher than the result for normal Beta nanocrystals with a similar Si/Al molar ratio. More importantly, the MMM-Beta catalyst showed a very high selectivity for the ester (94\%). In contrast, nanocrystalline zeolite Beta with very wide mesopore size distribution exhibited only $62 \%$ selectivity for the ester. Furthermore, Zr-doped zeolite silicalite-1 with a similar hierarchically micro-meso-macroporous structure (MMM-ZrS-1) presented high catalytic activity and selectivity for the cracking of large moleules [170].

As noted above, the catalytic performance of hierarchical porous zeolitic materials can be enhanced by improving their porous hierarchy, zeolitic crystallinity, and stability. Another efficient solution to enhance their catalytic performances is to introduce functionalized active sites or particles within the hierarchical porous system of zeolites. As we know, the high aromatic content in diesel fuel both decreases fuel quality and contributes significantly to the formation of undesirable emissions in exhaust gases [171-174]. One solution to this problem is deep saturation of aromatic hydrocarbons over noble-metal-supported catalysts. Compared to conventional supports, hierarchically porous zeolites not only served as a support, but also as an acidic catalyst due to their strong acidity. It has been reported that the catalytic activity and sulfur tolerance in deep hydrogenation of aromatic hydrocarbons can be enhanced by noble metals on acidic zeolitic supports [175187], which should be attributed to the partial electron transfer from the metal particles to the acidic sites of zeolitic supports
Table 4

Comparison of the catalytic behavior of Ru catalysts loaded on ZSM- 5 or meso-ZSM-5 with different acidities and porous structures for FT synthesis [184].

\begin{tabular}{|c|c|c|c|c|c|}
\hline \multirow{2}{*}{ Catalyst a } & \multirow{2}{*}{$\begin{array}{c}\text { CO } \\
\text { conver- } \\
\text { sion (\%) }\end{array}$} & \multicolumn{3}{|c|}{ Selectivity (\%) } & \multirow[b]{2}{*}{$C_{\text {iso }} / C_{n}$} \\
\hline & & $\mathrm{CH}_{4}$ & $\mathrm{C}_{2-4}$ & $\mathrm{C}_{5-11} \mathrm{C}_{\geq 12}$ & \\
\hline Ru/Na-ZSM-5 & 24.6 & 5.6 & 15.3 & 51.727 .4 & 0.8 \\
\hline Ru/H-ZSM-5 & 24.7 & 15.0 & 37.1 & 47.20 .7 & 2.7 \\
\hline $\mathrm{Ru} / \mathrm{meso}-\mathrm{ZSM}-5,0.1 \mathrm{~mol} / \mathrm{L}$ & 27.2 & 11.2 & 19.0 & 69.10 .7 & 2.1 \\
\hline $\mathrm{Ru} / \mathrm{H}-\mathrm{meso}-\mathrm{ZSM}-5,0.1 \mathrm{~mol} / \mathrm{L}$ & 33.0 & 14.3 & 26.8 & 58.80 & 2.2 \\
\hline Ru/meso-ZSM-5, 0.5 mol/L & 29.6 & 5.9 & 14.6 & 79.00 .5 & 2.7 \\
\hline $\mathrm{Ru} / \mathrm{H}$-meso-ZSM-5, $0.5 \mathrm{~mol} / \mathrm{L}$ & 26.4 & 7.0 & 22.7 & $70.3 \quad 0$ & 2.7 \\
\hline
\end{tabular}

Reaction conditions: catalyst $0.5 \mathrm{~g}, \mathrm{H}_{2} / \mathrm{CO}=1.0$, temperature $533 \mathrm{~K}$, pressure $2 \mathrm{MPa}$, total flow rate $20 \mathrm{ml} / \mathrm{min}$, time on stream $12 \mathrm{~h}$.

a The concentration given after meso-ZSM- 5 or H-meso-ZSM- 5 denotes the concentration of $\mathrm{NaOH}$ used for meso-ZSM-5 preparation.

$[188,189]$. For example, Tang et al. [180,181] demonstrated that an acidic mesoporous Beta zeolite-supported palladium catalyst exhibited higher activity for the deep hydrogenation of bulky aromatic pyrene than Pd/Beta, Pd/Al-MCM-41, and $\mathrm{Pd} / \gamma-\mathrm{Al}_{2} \mathrm{O}_{3}$ catalysts. Furthermore, the desulfurization effect of Pd/Beta-H was greater than that of Pd/Al-MCM-41 [181]. Sun et al. [182] prepared a series of Pt, Pd, and Pt-Pd catalysts supported on mesoporous zeolites, which exhibited much better catalytic performance for hydrodesulfurization. Christensen et al. [183] reported a series of mesoporous supported metal (Pt), alloy (PtSn), and metal carbide $\left(\beta-\mathrm{Mo}_{2} \mathrm{C}\right)$ catalysts. On conventional zeolites, the supported materials aggregated on the outer surface of the zeolite particles, particularly after thermal treatment. In contrast, the particles were evenly distributed throughout the mesoporous system of the zeolitic support, even after calcination, leading to nano crystals within mesoporous zeolite single crystals [183]. Very recently, Wang and co-workers $[184,185]$ prepared mesoporous zeolite supported ruthenium nano particles as highly selective Fischer-Tropsch (FT) catalysts for the production of $\mathrm{C}_{5}-\mathrm{C}_{11}$ isoparaffins (see Table 4). It was proved that both the mesoporous structure and the unique acidity of the meso-zeolites played crucial roles in tuning the product selectivity in FT synthesis [184]. The ruthenium catalyst loaded on meso-ZSM-5 prepared using a $\mathrm{NaOH}$ concentration can produce $\mathrm{C}_{5}-\mathrm{C}_{11}$ hydrocarbons with a selectivity of about $80 \%$. Furthermore, Jin et al. [186] used hierarchical MFI zeolite as a support for the immobilization of a $\mathrm{Pd}(\mathrm{OAc})_{2}$-ionic liquid matrix. The resultant catalyst exhibited excellent catalytic activity and high stability for Suzuki coupling reactions in water. Choi et al. [187] reported the preparation of $\mathrm{Pd}^{2+-}$-exchanged mesoporous sodalite and $\mathrm{NaA}$ zeolite. Notably, $\mathrm{Pd}^{2+}$-exchanged on the zeolite frameworks were highly stabilized against metal agglomeration, maintaining high catalytic activities during a number of recycles under aerobic environments for various C-C coupling reactions of bulky aryl compounds.

\subsubsection{Oxidation catalysts}

Titanium silicate-1 (TS-1) developed by Enichem [190,191] is a redox molecular sieve with MFI structure, in which isolated titanium sites in the zeolite framework act as active sites. This 
development aroused large interest in zeolite and heterogeneous catalysis research. TS- 1 is an active, highly selective, and environmentally benign oxidation catalyst for a number of principle industrial organic oxidation reactions which use $\mathrm{H}_{2} \mathrm{O}_{2}$ as oxidant. Typical reactions include the conversion of alkanes to alcohols and ketones, secondary alcohols to ketones, secondary amines and ammonia to dialkylhydroxylamines and hydroxylamine, as well as alkene epoxidation, phenol oxidation, ketone ammoximation, etc. [192-198]. It was noted that the TS- $1 / \mathrm{H}_{2} \mathrm{O}_{2}$ catalytic system was successfully commercialized in 2003 by Simitomo Chemical Co., Ltd. for the selective ammoximation of cyclohexanone to the corresponding oxime. In early 2009, BASF, applied TS- 1 on the scale of $300000 t$ to a process for the clean synthesis of propylene oxide [199]. However, the small pore apertures of TS- 1 limit its applications to reactions with small molecules, typically linear alkanes or alkenes, or monosubstituted aromatic compounds such as phenol, anisole, and aniline. For this reason, diffusion limitations are of particular importance, and it was reported that a slight increase in the crystal size could drastically affect the activity [200,201]. Molecular transport in zeolite channels can be improved by decreasing the particle size or creating additional meso/macro porosity. Therefore, many efforts have been made to develop TS-1 zeolite with a hierarchical porous structure.

Schmidt et al. [202] first reported the synthesis of hierarchical mesoporous TS- 1 with a mesopore size of $20 \mathrm{~nm}$ using carbon black as a hard template. The resultant hierarchical mesoporous TS- 1 exhibited approximately the same catalytic activity as conventional TS- 1 in the oxidation of 1-octene but far surpassed the latter in the epoxidation of cyclohexene. Lee et al. [203] reported the synthesis of large monolithic zeolite TS- 1 foams with variable macropore architectures from the utilization of poly-urethane foams (PUFs). Ke et al. [204] presented a one-pot synthesis method to prepare TS-1 zeolite with mesoporous structure by simply adding triethanolamine (TEA) into a TS-1 synthesis solution, followed by hydrothermal synthesis or a dry-gel conversion technique. The result showed that TS-1 synthesized by a dry gel conversion technique exhibited higher benzene hydroxylation activity than that prepared by hydrothermal synthesis when the same amount of triethanolamine was added. Fang and Hu [205] demonstrated that the synthesis of a mesoporous TS-1 zeolite with an additional mesopore system formed by the packing of the TS- 1 nanocrystals was possible when using the mesoporous carbon material (CMK-3) as a hard template. The hierarchical mesoporous TS-1 zeolite showed improved catalytic performance for thiophene oxidation in comparison with common TS-1 and was able to catalyze the oxidation of bulky sulfur containing molecules such as dibenzothiophene (DBT). The results showed that it took $5 \mathrm{~h}$ to achieve complete oxidation of thiophene over common TS-1, while thiophene and DBT could be completely oxidized after $1 \mathrm{~h}$ over a meso-TS-1 catalyst. Wang et al. [206] reported the synthesis of hollow TS-1 crystals with large intra-crystalline voids via a dissolution/recrystallization process. Recently, they also succeeded in preparing a TS-1 zeolite with hierarchical mesoporous/microporous structure in the presence of an organosilane surfactant. Of note is the fact that the
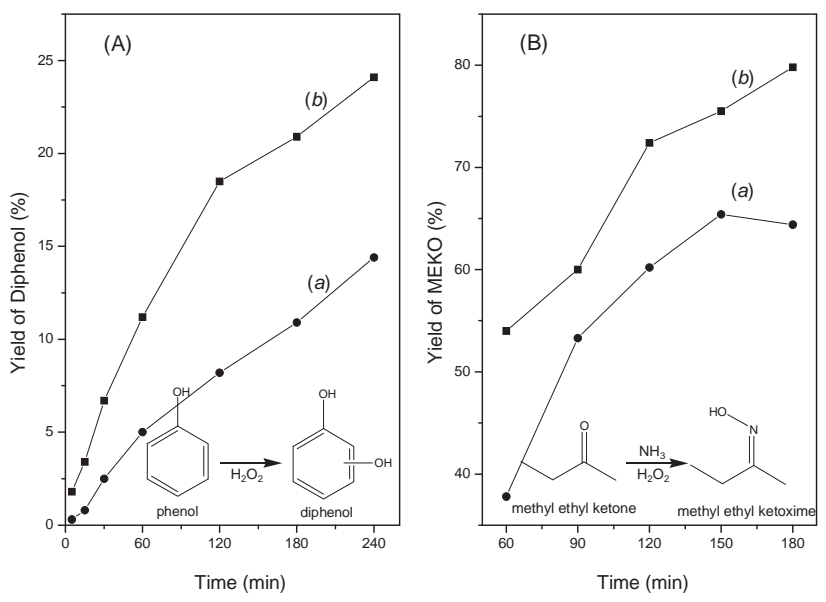

Fig. 10. Yields of diphenol (catechol and hydroquinone) (A) and the yields of methyl ethyl ketoxime (MEKO) (B) as a function of reaction time for TS-1 (a) and meso-TS-1 (b) [209].

content and coordination of Ti species in the framework were not affected by the presence of the organosilane surfactants [207]. The resultant mesoporous TS-1 zeolites have been used as catalysts in various oxidation reactions with aqueous $\mathrm{H}_{2} \mathrm{O}_{2}$. Serrano et al. [208] demonstrated an effective method for the fabrication of hierarchical TS-1 zeolites based on the crystallization of silanized seeds. The hierarchical TS-1 possessed a secondary porosity in the range of supermicro- and mesopores, in addition to the typical microporosity of MFI-type materials. These resultant hierarchically porous TS-1 catalysts showed higher conversion rates $(42.1 \%)$ in the epoxidation of 1-octene with tertbutylhydroperoxide (TBHP) than conventional TS-1 zeolite (5.6\%), while maintaining $100 \%$ epoxide selectivity and very high oxidant efficiencies. Xin et al. [209] synthesized a TS-1 zeolite with a disordered network of mesopores penetrating the microporous crystalline zeolite framework by a one-pot approach using carbon hard-templating. The obtained hierarchical mesoporous TS-1 zeolite exhibited high activities and selectivities for various oxidation reactions (Fig. 10). Phenol conversion in the hydroxylation of phenol over meso-TS-1 was 33\%. However, the conversion rate obtained over conventional TS-1 was only $19.3 \%$ under identical reaction conditions (Fig. 10(A)). Furthermore, the methyl ethyl ketoxime (MEKO) yield of meso-TS-1 was considerably higher than that of TS-1. Conversion on meso-TS-1 was $80.2 \%$, significantly higher than that on conventional TS-1 (64.9\%, Fig. 10(B)). Zhou et al. [118] reported the synthesis of a new hierarchical mesoporous TS-1 type zeolite by a simple steam-assisted crystallization method. The product exhibited high catalytic activity and a greatly prolonged lifetime in the selective oxidation of 2,3,6-trimethylphenol (TMP) to trimethyl- $p$-benzoquinone (TMBQ). As the sizes of both TMP and TMBQ molecules are larger than the diameter of the micropores in TS-1 zeolite (ca. $0.55 \mathrm{~nm}$ ), TS-1 was ineffective for the selective oxidation of such bulky reactants due to the diffusion difficulty of reactants and products in its channel systems. In contrast, it is worth noting that the 2,3,6-trimethylphenol conversion in the first cycle using c-Ti-TUD-1 as catalyst was as high as ca. 99\%; then 


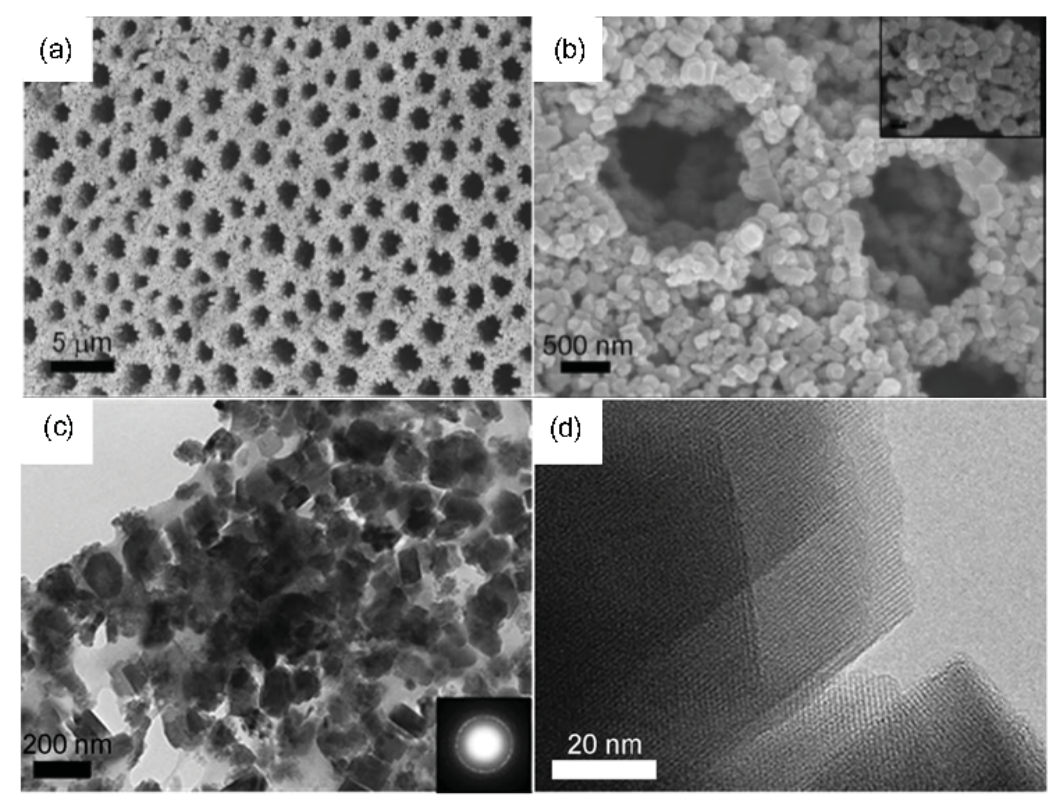

Fig. 11. SEM (a,b) and TEM (c,d) investigations of 6 micro-meso-macroporous zeolite TS-1 (MMM-TS-1(3)) [210].

decreased to $86 \%$ in the next cycle but remained unchanged at about $80 \%$ in the following cycles.

Very recently, Chen et al. [210] following their previous successes $[15,168-170]$ developed a quasi-solid-state crystallization process to synthesize hierarchical micro-meso-macroporous TS-1 zeolite (MMM-TS-1(3)) with well-defined macropores, uniform mesopores, and zeolitic micropores (Fig. 11). The titanosilicate catalysts not only contained thermally stable TS-1 nanocrystals with meso-macroporous structures, but they also showed high thermal stability themselves. The novel hierarchical pore structure and improved stability resulted in catalysts that exhibited superior catalytic performances compared to normal zeolite TS-1 nanocrystals, especially for the epoxidation of larger molecules [210]. For styrene oxidation, styrene conversion with MMM-TS-1(3) catalysts could reach $85 \%$, which was higher than that obtained over normal TS-1 nanocrystal catalysts (72\%, see Table 5). Furthermore, the selectivity of MMM-TS-1(3) catalysts was far superior to that of TS-1 nanocrystals. Only benzaldehyde and benzoic acid were obtained in the epoxidation of styrene over MMM-TS-1(3) catalysts. Noteworthily, the conversion in the epoxidation of larger molecules (2,4,6-trimethylstyrene) with MMM-TS-1(3) as catalysts reached $45 \%$, as opposed to just $5 \%$ for TS- 1 nanocrystals, as 2,4,6-trimethylstyrene molecules are too large to enter the micropore channels of the nanocrystals (see Table 5). Furthermore, the recycled active sites of $\mathrm{Ti}$ species in MMM-TS-1(3) still show comparable activities to that of the initial cycle.

As mentioned above, various active interiors, such as $\mathrm{Fe}_{2} \mathrm{O}_{3}$ [71,78], Ag [75,78,80,81], PdO [75], and Pt [80] nanoparticles can easily be entrapped inside the hollow zeolite capsules by pre-incorporating the guest species into the mesopores of the MS templates. These hierarchical porous zeolites with functionalized interiors have also been used as catalysts for various oxidation reactions. For example, hollow zeolitically microcapsulized HZMC catalysts of Pt@S1 and Ag@S1 behaved extremely well in these respects for the catalytic oxidation of alcohols in both liquid and gas phases [80]. Their reactant selectivity, poison resistance, and reusability greatly exceeded those of ordinary commercial catalysts, such as $\mathrm{Pt} / \mathrm{SiO}_{2}$ and $\mathrm{Pt} / \mathrm{Al}_{2} \mathrm{O}_{3}$. Furthermore, the catalysts could be recycled for at least 6 runs without losing their activity, whereas the commercial catalysts deactivated rapidly on recycling [80].

As previously mentioned, the key factor that restricts a wider range of industrial applications of conventional zeolitic materials is their pore size. The low mass transport within the

\section{Table 5}

Catalytic activities for the epoxidation of styrene and 2,4,6-trimethylstyrene over normal TS-1 nanocrystals and MMM-TS-1(3) products, and the structural parameters obtained through BET for various samples [210].

\begin{tabular}{|c|c|c|c|c|c|c|c|c|c|c|}
\hline \multirow{2}{*}{$\mathrm{S}_{\mathrm{N}}$} & \multirow{2}{*}{$\begin{array}{c}\text { Conversion } \\
(\%)\end{array}$} & \multirow{2}{*}{$\begin{array}{c}A_{\mathrm{BET}} \\
\left(\mathrm{m}^{2} / \mathrm{g}\right)\end{array}$} & \multirow{2}{*}{$\begin{array}{l}\mathrm{Si} / \mathrm{Ti} \\
\text { ratio }\end{array}$} & \multicolumn{7}{|c|}{ Product selectivity (\%) } \\
\hline & & & & P1 & P2 & P3 & P4 & P5 & P6 & $\mathrm{Pt}$ \\
\hline & 72 & 260 & 98 & 9.5 & 63.5 & 4.0 & 9.5 & 13.5 & - & \\
\hline & & 58 & 104 & - & 82.4 & 17.6 & - & - & - & \\
\hline & & & 98 & 100 & - & - & - & - & - & \\
\hline & & 58 & 104 & 50 & 10.3 & 6.8 & 10.0 & 5.4 & 14.0 & \\
\hline $\mathrm{S}_{2} \mathrm{b,c}$ & 31 & 580 & 104 & 49 & 9.7 & 8.3 & 10.1 & 6.1 & 14.4 & \\
\hline
\end{tabular}

All the samples were calcined at $550{ }^{\circ} \mathrm{C}$ for $5 \mathrm{~h}$. S1: TS-1 nanocrystals. S2: MMM-TS-1(3).

a Styrene epoxidation: $10 \%$ catalysts, styrene: $\mathrm{H}_{2} \mathrm{O}_{2}=1: 2$, reaction time $=$ $8 \mathrm{~h}$, the products are styrene oxide (P1), benzaldehyde (P2), benzoic acid (P3), 1-phenyl-etan-1,2-diol (P4), and others (P5).

b 2,4,6-Trimethylstyrene epoxidation: $10 \%$ catalysts, 2,4,6-trimethyl styrene: $\mathrm{H}_{2} \mathrm{O}_{2}=1: 2$, reaction time $=8 \mathrm{~h}$, the products are 2,4,6-trimethyl- styrene oxide (P1), 2-mesitylene-carboxylic acid (P2), 2,4,6-trimethyl- benzaldehyde (P3), 2,4,6-trimethyl-acetophenone (P4), 2,4,6-trimethyl- phenylacetic acid (P5), 2,4,6-trimethyl-hyacinthin (P6), and others (P7).

${ }^{\mathrm{C}}$ Sample was recycled after being calcined at $550{ }^{\circ} \mathrm{C}$ for $5 \mathrm{~h}$ and reused in 2,4,6-trimethylstyrene epoxidation. 
micropore apertures limits the performance of industrial catalysts. The introduction of additional large pores into zeolites to form hierarchical porous zeolites has been considered as the optimal solution to fix the problem of diffusion limitations and enhance catalytic activities.

\subsection{Hierarchically porous metal oxides}

Hierarchically porous metal oxides are used in a variety of applications, such as adsorption, catalysis, energy conversion, and storage, or in biomaterials [211-218]. The advantage of these types of hierarchical metal oxides as catalysts is that additional large pores give the materials large transport channels accompanied by a high active surface area, which leads to the improvement of their catalytic performance in various reactions. The majority of reports on the fabrication of hierarchical porous metal oxides deal with systems containing different scales of pores. In this section, representative synthetic approaches in the preparation of hierarchically porous metal oxides have been summarized combining with their catalytic applications for various reactions.

\subsubsection{Templating methods}

Templating is an important and common method to fabricate hierarchical porous metal oxides. A representative example that employs a nanocasting route to prepare hierarchically porous cobalt oxide, tin oxide, and manganese oxide monoliths by using hierarchical meso-macroporous silica monoliths as hard templates has been reported by Smatt et al. [219,220]. Here, the starting silica monoliths prepared through a straightforward sol-gel process with a macropore size in the range of 0.5-30 $\mu \mathrm{m}$ and mesopores varying between 3-30 nm were used as hard templates. Then, the hard templates were then impregnated with a metal salt solution, which was subsequently decomposed to a metal oxide by heat treatments to form a $\mathrm{SiO}_{2} / \mathrm{MeO}_{x}$ composite. Finally, the hard templates could be removed by leaching in either $\mathrm{NaOH}$ or hydrofluoric acid [219].

In addition, polymer spheres with macroscale size and surfactants with a mesoscale size have also been used as templates to introduce macropores and mesopores into metal oxides. For example, Drisko et al. [221] described a reproducible one-step method for the preparation of metal oxides with controllable hierarchical pore architectures using polyfurfuryl alcohol particles and pluronic F127 as macroporous and mesoporous templates, respectively. Independent control over the mesoand macropore morphology could be achieved by adjusting the molar ratio of the templates to the silica/metal oxide precursor. Dionigi et al. [222] employed a colloidal composite acting as a structure directing agent for the fabrication of $\mathrm{TiO}_{2}$ films with a controlled and geometrically ordered porosity on different length scales by a fluidic technique and subsequent annealing. Very recently, Mandlmeier et al. [223] reported the preparation of hierarchical periodic titania nanostructures composed of a macroporous crystalline scaffold and mesoporous titania by using polymethylmethacrylate spheres as a macroporous template and surfactant pluronic P123 as a mesoporous template.

\subsubsection{Self-formation phenomenon}

An innovative self-formation procedure developed around the basis of metal alkoxide chemistry proposed by our group has been thoroughly reported and used to synthesize hierarchically porous metal oxides since 2003 [224-253]. In this spontaneous self-formation phenomenon, the hydrolytic condensation chemistry is the key factor in determining the structure of the final oxide product. It has been considered that this self-formation phenomenon to fabricate hierarchical porous oxides is a simple and efficient method. In fact, Yaldas [224] reported firstly the synthesis of macroporous structures using titanium ethoxide under alkaline conditions in 1986. However, the presence of the porous hierarchy in the final materials and the formation mechanism were not revealed. Antonelli [225] demonstrated the successful synthesis of niobium oxide with macro-mesoporous structure using niobium ethoxide in 1999 and they attributed the success to the presence of a ligand-assisted vesicle used as templates. Subsequently, a series of hierarchically porous oxides prepared via a surfactant-assisted synthesis which again exploited metal alkoxide chemistry has been reported both by $\mathrm{Su}$ et al. and Shanks et al.[6,13,18,226-232] By this method, various hierarchically porous metal oxides have been successfully obtained, which

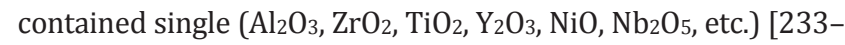
236] and multiple (mixed oxides and phosphates) [237-243] chemical compositions. Scientists found that hierarchically porous oxides can also be achieved by a dropwise addition of various metal alkoxides into an aqueous solution in the absence of surfactant [244-260]. These results suggested that the hierarchical porosity is only dependent on the metal alkoxides and solution used, indicating that the reactivity of a metal alkoxides and the nature of the alcohol by-product should be important factors in controlling this self-formation phenomenon. On the basis of a large series of experiments and the direct observation by optical microscope, Su et al [12,14,15,18,228,240,245-261] demonstrated that surfactant molecules added in the synthesis medium can affect only the textural properties but not play the role in the creation of porous hierarchy. This important discovery not only clarified the long discussion on the role of surfactant molecules in the formation of hierarchical porosity, but also provided solid proofs on the formation mechanism they proposed [12,14,15,18,228,240,245-261]. Su's pionieer work, the invention of a very simple, environmentally friendly, low cost procedure, opened a prospect avenue in the design of hierarchically porous materials and their applications and can lead to the concretisation of "Hierarchical Catalysis" concept $[12,228,239,240,251,255]$. In this part, we will summarize recent developments that have been achieved in the field of hierarchically porous oxides obtained by this self-formation phenomenon.

Figures 12 and 13 show SEM and TEM images of hierarchically porous metal oxides with different hierarchically porous structures and chemical compositions, synthesized via a spontaneous self-formation process. For example, various hierarchically porous metal oxides with one chemical composition, such as $\mathrm{ZrO}_{2}[226,227,233,234,244-246], \mathrm{TiO}_{2}$ [236,247], $\mathrm{Al}_{2} \mathrm{O}_{3}$ $[235,249], \mathrm{Y}_{2} \mathrm{O}_{3}$ [240], $\mathrm{NiO}$ [240] and other oxides [226-261, 


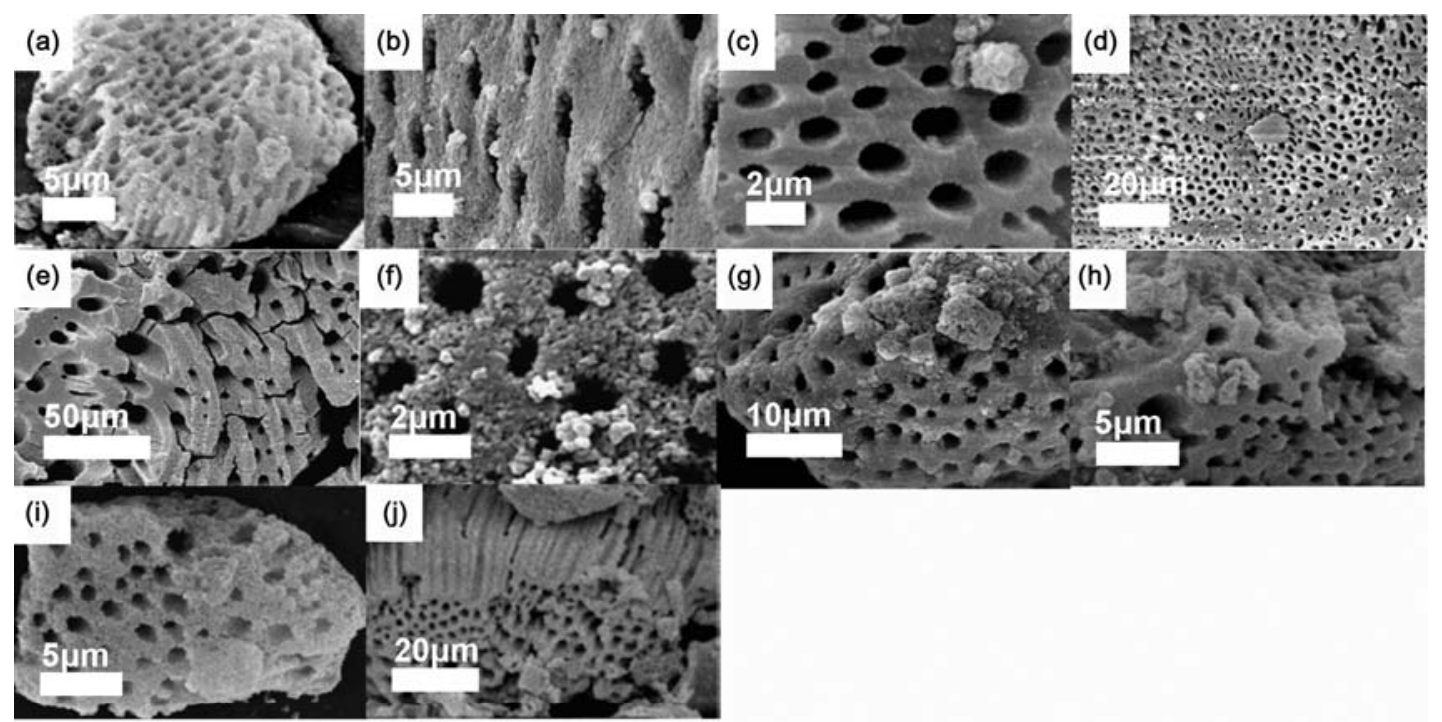

Fig. 12. SEM images of hierarchically meso-macroporous metal oxides obtained by a spontaneous self-formation process [240]. (a) $\mathrm{ZrO}_{2}$; (b) $\mathrm{TiO}_{2}$; (c) $\mathrm{Al}_{2} \mathrm{O}_{3}$; (d) $\mathrm{Y}_{2} \mathrm{O}_{3}$; (e) $\mathrm{Nb}_{2} \mathrm{O}_{5}$; (f) $\mathrm{TiO}_{2}-\mathrm{ZrO}_{2}$; (g) $\mathrm{TiO}_{2}-\mathrm{Al}_{2} \mathrm{O}_{3}$; (h) $\mathrm{Al}_{2} \mathrm{O}_{3}-\mathrm{ZrO}_{2}$; (i) $\mathrm{ZrO}_{2}-\mathrm{SiO}_{2}$; (j) $\mathrm{Al}_{2} \mathrm{O}_{3}-\mathrm{SiO}_{2}$.

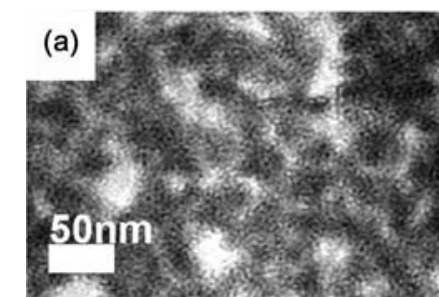

(d)

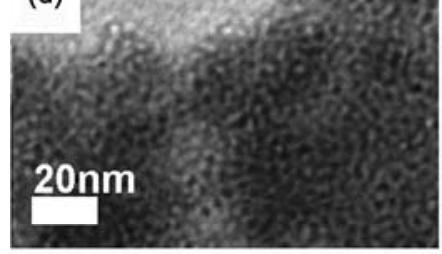

(e)
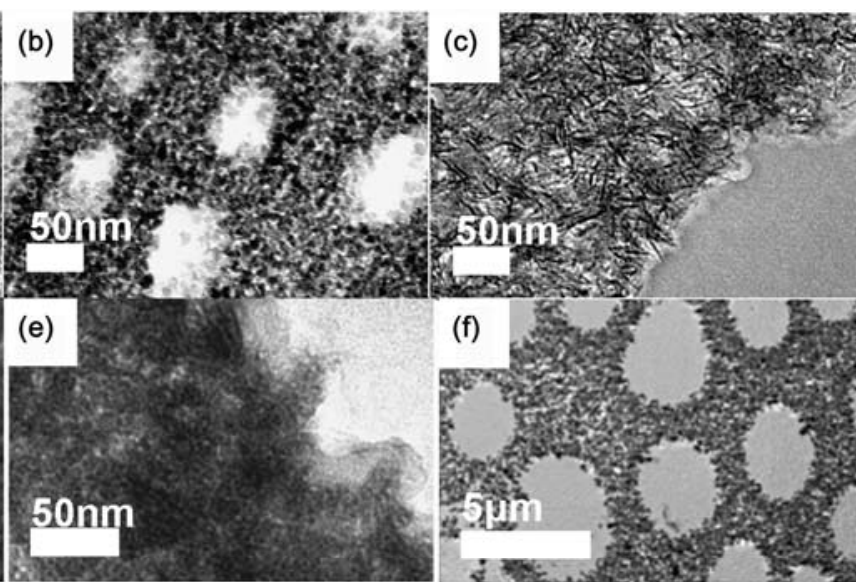

Fig. 13. TEM images of hierarchically meso-macroporous metal oxides obtained by a spontaneous self-formation process [240]. (a) $\mathrm{ZrO}_{2}$; (b) $\mathrm{TiO}_{2}$; (c) $\mathrm{Al}_{2} \mathrm{O}_{3} ;$ (d) $\mathrm{TiO}_{2}-\mathrm{ZrO}_{2}$; (e) $\mathrm{TiO}_{2}-\mathrm{Al}_{2} \mathrm{O}_{3} ;$ (f) $\mathrm{ZrO}_{2}-\mathrm{SiO}_{2}$.

265-271] have been prepared from a single metal alkoxide precursor (Fig. 12(a)-(e) and Fig. 13(a)-(c)). Furthermore, this synthesis strategy based on a self-formation phenomenon of porous hierarchy demonstrated its simplicity and superiority in the preparation of a series of hierarchical meso-macroporous binary mixed metal oxides. Bimodal binary oxides featuring multiple porosity, including titania-zirconia (TZ) [238-240], titania-alumina (TA) [238-240], alumina-zirconia (AZ) [238-240], zirconia-silica (ZS) [238-240], and aluminosilicates [238-240,248,251] have been prepared by the use of mixed alkoxide solutions (Fig. 12(f)-(j) and Fig. 13(d)(f)). The powder and monolith particles prepared by this self-formation phenomenon exhibit a unique morphology in which macropores with micro/mesoporous walls traverse through the particle. This simple synthetic method produces very pure oxide materials starting with just the metal alkoxide precursors in aqueous solution. Furthermore, this spontaneous self-formation process that gives rise to hierarchically structured materials can occur under a wide range of synthetic conditions, such as different $\mathrm{pH}$ and temperature, and in the pres- ence or absence of a surfactant or a co-solvent. Macroporous structures with different morphologies, including funnel-like [226,233,234,236,240,244-247], tubular [235,249], and 3D open macroporous structures [253], have been observed in the resultant hierarchically porous materials. Mesoporous structuration in the macropore walls of various hierarchically porous oxides can arise from the aggregation of nanoparticles [226,243,244,236,238-240,244-247], nanofibers [235,249] and nanorods [253], respectively. Moreover, compared to single metal oxides, hierarchical meso-macrostructured binary mixed oxides display higher surface areas and larger pore volumes as well as different crystalline phases, indicating that the addition of a secondary oxide results in crystal modification. The mesopore and macropore sizes can be tailored by adjusting the stoichiometry and higher thermal stabilities have been evidenced. Such modulable monolithic materials with multiscaled pore sizes and a wide variety of chemical compositions should be promising for multiple applications in catalysis and separation technology.

To explain the formation of porous hierarchy arising from 
metal alkoxide chemistry, many formation mechanisms have been proposed. For example, Antonelli [225] has described a surfactant procedure. Deng et al. [229] suggested that the emulsified state generated the mesoporous structure, and an extended cylindrical bilayer organized by the surfactant resulted in the generation of macropores. Our group at first [226] proposed a surfactant assembly mechanism since the role of the surfactant was elusive at that time. Furthermore, a nanoparticle aggregation mechanism and a microphase-separated mechanism have been proposed by Shanks et al. [230,231] and Collins et al. [254], respectively. To study the formation mechanism in depth, we firstly used a high-resolution optical microscope in the in situ study of this spontaneous self-formation procedure [228,240,251,252,257-260]. A controlled polymerization of zirconium tetrapropoxide was performed by adding it dropwise into a $2 \mathrm{ml}$ aqueous film and the reaction and generation of the macrostructure in the oxide product was observed in situ by optical microscopy. The observations made clearly suggest a mechanism based on the synergy between the polymerization kinetics of the inorganic precursor and water molecules, that is, simultaneous formation of mesoporosity and macrochannels. It can be found that the key point of this spontaneous self-formation procedure is thus the very high rate at which the hydrolyzed metal alkoxides undergo condensation reactions in aqueous solution. In particular, alcohol molecules can be generated suddenly as soon as the metal alkoxide precursor is in contact with water, and the amount of alcohol produced will quickly increase as the reaction progresses because one metal alkoxide molecule can produce at least two more alcohol molecules. On the basis of observation, a "porogen" formation mechanism has been proposed by our group [228,240,251,252,255,257-260]. Very recently, we have successfully observed the pattern of straight and parallel macrochannels in the droplet using high-resolution optical microscopy (OM) [252]. The OM image revealed visible macrochannels in only a few seconds after introducing the droplet of titanium alkoxide into water, confirming the above proposal. The alcohol and water molecules released by this spontaneous polymerization can only be expelled toward the center of the droplet because of the formation of a dense translucent gelatinous and semipermeable shell and also because of the high miscibility of alcohol molecules in the unconsumed zirconium propoxide left at the center of the drop. All the alcohol and water molecules then gather together leading to the formation of larger water/ethanol macrochannels inside the structure. The formation of funnel-like or straight macrochannels is direct evidence that these macrochannels are formed by the sudden release of alcohol and water molecules during rapid hydrolysis and condensation. These in situ studies by direct observations can provide a lot of knowledge on the chemistry of metal alkoxides and the formation mechanism of metal oxides from such alkoxides. Furthermore, gas molecules have also been employed as the self-generated porogen in the fabrication of hierarchically porous oxides [253]. We have developed a simple and spontaneous one-pot self-formation procedure that was easy to scale up based on the chemistry of trimethylaluminum (TMA), leading to thermally stable crystalline macroporous alumina with a very unique and unprecedented 3D hierarchical pore structure consisting of well-defined wormlike mesopores [253]. In this work, the methane molecules released during the very fast and spontaneous reaction between TMA and the hydroxyl groups of water played the role of a porogen like the alcohol molecules do during the hydrolysis and condensation of metal alkoxides. In spite of the high reaction rate, the release of methane molecules during the hydrolysis reaction is quite homogeneous, leading to very homogeneous mesoporous nanorods which assemble in such a fashion that macrocavities are formed. This kind of structure allows the rapid discharge of the large quantity of methane molecules instantaneously released from the hydrolysis of TMA. This self-formation phenomenon based on the porogen mechanism can open novel perspectives toward the elaboration of other types of interesting meso(micro)-macroporous materials.

On the basis of this self-formation phenomenon, various available methodologies have been developed to fabricate hierarchically porous materials with remarkable structures and functions. A significant development in the methodologies is that this spontaneous process was extended to combine with other strategies for the fabrication of hierarchically porous materials with specific structures and functions. For example, hierarchically meso-macroporous carbons were prepared by a combination of self-formation and template replicate [255]. Hierarchically porous zeolitic materials with organized micro-meso-macroporous zeolitic architectures have been developed by a combination of self-formation and zeolitic crystallization procedures [168-170,210]. Furthermore, bimodal nanoporous aluminosilicates with a hierarchically macroporous core inside an ordered mesoporous shell were synthesized
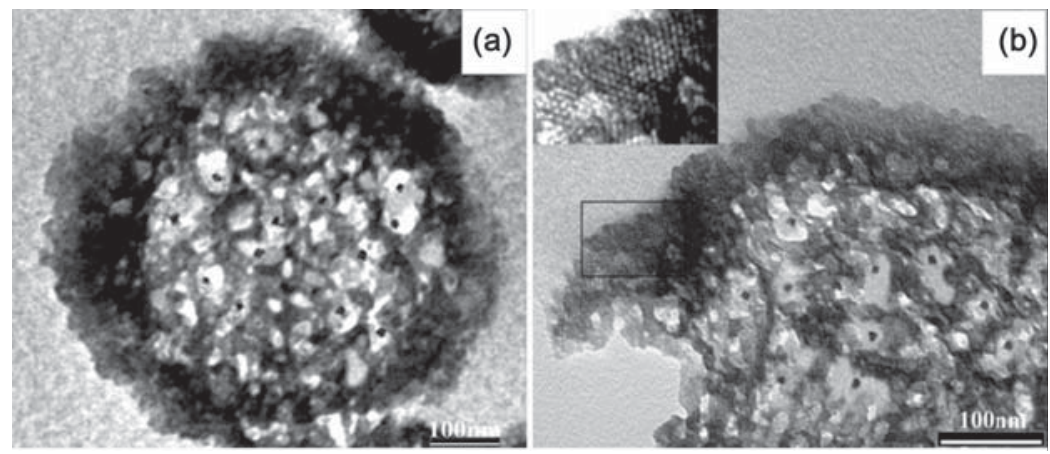

Fig. 14. TEM and HRTEM images of calcined encapsulated $\mathrm{Fe}_{2} \mathrm{O}_{3}$ particles into the macroporous core [256]. 
Table 6

Composition, surface area, and catalytic activity [256].

\begin{tabular}{|c|c|c|c|c|c|c|c|}
\hline \multirow{2}{*}{ Sample } & \multirow{2}{*}{$\mathrm{Si} / \mathrm{Fe}$} & \multirow{2}{*}{$A_{\mathrm{BET}} /\left(\mathrm{m}^{2} / \mathrm{g}\right)$} & \multicolumn{2}{|c|}{ Conversion (\%) } & \multicolumn{3}{|c|}{ Selectivity (\%) } \\
\hline & & & Phenol & $\mathrm{H}_{2} \mathrm{O}_{2}$ & Benzoquinone & Catechol & Hydroquinone \\
\hline EncapsulatedFe $\mathrm{O}_{3}$ (1) & 78 & 821 & 22.5 & 78.6 & 5.8 & 61.1 & 33.1 \\
\hline EncapsulatedFe $\mathrm{O}_{3}(5)$ & 81 & 619 & 20.4 & 74.3 & 4.8 & 63.7 & 31.5 \\
\hline MCM-41 & & 1023 & 0 & 0 & 0 & 0 & 0 \\
\hline Fe-MCM-41 & 59 & 905 & 7.1 & 25.3 & 1.8 & 52.1 & 46.1 \\
\hline $\mathrm{Fe}_{2} \mathrm{O}_{3}$ & & 29 & 7.3 & 63.2 & 9.0 & 57.9 & 33.1 \\
\hline
\end{tabular}

through a combination of self-formation and templating strategies (Fig. 14) [256]. Most interestingly, the method of core/shell-structure synthesis was precisely applied to nanoreactor design, to generate new functionalities by in situ encapsulation of metal oxide nanoparticles inside the core/shell structure. A highly efficient nanoreactor was obtained by the encapsulation of size-controlled $\mathrm{Fe}_{2} \mathrm{O}_{3}$ nanoparticles with a hierarchically macroporous core@ordered mesoporous shell system (Fig. 14). Significantly, encapsulated $\mathrm{Fe}_{2} \mathrm{O}_{3}$ nanoparticles were very active for the catalytic conversion of phenol. The conversion of phenol was $22.5 \%$, which was much higher than that of reference catalysts MCM-41, Fe-MCM-41, and $\alpha-\mathrm{Fe}_{2} \mathrm{O}_{3}$. It is worth noting that the nanoreactor still showed comparable activities to that of the initial ones (see Table 6). This is because of the fact that the mesoporous shell could prevent leaching of the metal oxide nanoparticles that are formed inside the macroporous core as well as allow the diffusion of chemical reagents toward the active sites within. In addition, other active species, such as metallic nanoparticles, organometallics, and even biological species, can be encapsulated by this one-pot-synthesis strategy. This novel core/shell structure can be exploited in the design of magnetic devices, sensors, and rechargeable lithium batteries. Furthermore, our group demonstrated the preparation of hierarchically meso-macroporous aluminosilicates with sponge-like or spherical voids and of high tetrahedral aluminium content on the basis of the aqueous polymerisation of a new stabilized alkoxy-bridged single molecular precursor, an aluminosilicate ester (sec-BuO) 2 -Al-O-Si(OEt) 3 [257-260]. The resultant hierarchically structured meso-macroporous aluminosilicates showed higher catalytic activity in the esterification of free fatty acid (FFA) oils than commercial Bentonite clay [257].

Reaction conditions: water as a solvent, temperature $80{ }^{\circ} \mathrm{C}$, phenol $/ \mathrm{H}_{2} \mathrm{O}_{2}=3: 1$ (molar ratio), reaction time for $4 \mathrm{~h}$, catalyst $/$ phenol $=5 \%$ (weight ratio). Hierarchically porous metal oxides obtained on the basis of the aforementioned spontaneous self-formation phenomenon are considered as very competitive candidates for use as catalytic supports. Various noble-metal-based catalysts supported on these hierarchically meso-macroporous metal oxides have been successfully developed for the total oxidation of volatile organic compounds (VOCs) [261]. Hierarchically meso-macroporous metal oxides, such as $\mathrm{TiO}_{2}, \mathrm{ZrO}_{2}$, binary systems (mixed $\mathrm{TiO}_{2}-\mathrm{ZrO}_{2}$ ), as well as metal-oxide doped meso-macroporous $\mathrm{TiO}_{2}$ (examples include $\mathrm{Nb}_{2} \mathrm{O}_{5}-\mathrm{TiO}_{2}, \mathrm{CeO}_{2}-\mathrm{TiO}_{2}$, and $\mathrm{V}_{2} \mathrm{O}_{5}-\mathrm{TiO}_{2}$.) have been used as supports for $\mathrm{Au}, \mathrm{Pd}$, and $\mathrm{Pt}$. These noble-metal-based catalysts supported on hierarchically meso-macroporous metal oxides present superior catalytic performances for the total oxidation of VOCs [262-270]. For example, hierarchically meso-macroporous catalytic materials, $\mathrm{Pd} / \mathrm{ZrO}_{2}, \mathrm{Pd} / \mathrm{TiO}_{2}$, and $\mathrm{Pd} / \mathrm{ZrO}_{2}-\mathrm{TiO}_{2}$, exhibited very high catalytic activities and low coke content for the oxidation of toluene at low temperature [262-264]. All these Pd impregnated catalysts were found to be powerful catalysts because they were active at low temperature and were totally selective for $\mathrm{CO}_{2}$ and $\mathrm{H}_{2} \mathrm{O}$ in toluene oxidation. However, during the oxidation of chlorobenzene, production of polychlorinated compounds $\mathrm{PhCl}_{x}$ (with $x=2-6$ ) occurred at low temperature however the amount of $\mathrm{PhCl}_{x}$ significantly decreased over $\mathrm{Pd} / \mathrm{TiO}_{2}-\mathrm{ZrO}_{2}$ compared to $\mathrm{Pd} / \mathrm{TiO}_{2}$. Nevertheless, the chlorobenzene was readily converted into $\mathrm{HCl}, \mathrm{CO}_{2}$, and $\mathrm{H}_{2} \mathrm{O}$ at temperatures higher than 530 ${ }^{\circ} \mathrm{C}$ but with some modifications of the catalysts observed after testing [262]. Furthermore, Pd- and/or Au loaded Ce-, Nb- and V-doped meso-macroporous $\mathrm{TiO}_{2}$ and $\mathrm{TiO}_{2}-\mathrm{ZrO}_{2}$ catalyst supports exhibited much higher activities than that of the unloaded supports in oxidation reactions [269-271].

\subsubsection{Selective leaching}

Selective leaching has been used to synthesize a variety of porous inorganic monoliths. Generally, a composite with two immiscible phases obtained by some physical mixing method are used as a precursor. The two phases in the precursor are in intimate contact with one another. A porous monolith of the desired phase can be synthesized by selective leaching of one sacrificial phase from the prepared precursor in an appropriate solution. By this method, various porous monoliths have been successfully prepared [272-280]. Recently, porous materials with hierarchical porous structures can also be prepared by subsequent leaching of sacrificial phases from the macropore walls [281-291]. Currently, most of the hierarchical porous materials obtained by a selective leaching method are metal oxides or metals. Panda et al. [288] described a schematic representative on the formation mechanism of hierarchical porous materials obtained by a selective leaching method, which is helpful in understanding the selective leaching process (Fig. 15). Firstly, a composite with two immiscible phases ( $\mathrm{NiO}$ and $\mathrm{ZnO}$ ) is obtained from $\mathrm{Ni}^{\mathrm{II}}$ and $\mathrm{Zn}^{\text {II }}$ nitrates in solution with urea by an evaporation and combustion synthetic preparation process (Fig. 15a and b). Firing of the precursor followed by suitable sintering results in a monolith comprised of $\mathrm{NiO}$ and ZnO particles, which were intimately dispersed (Fig. 15c). Then, the $\mathrm{ZnO}$ particles in the monoliths can be leached in alkali to 


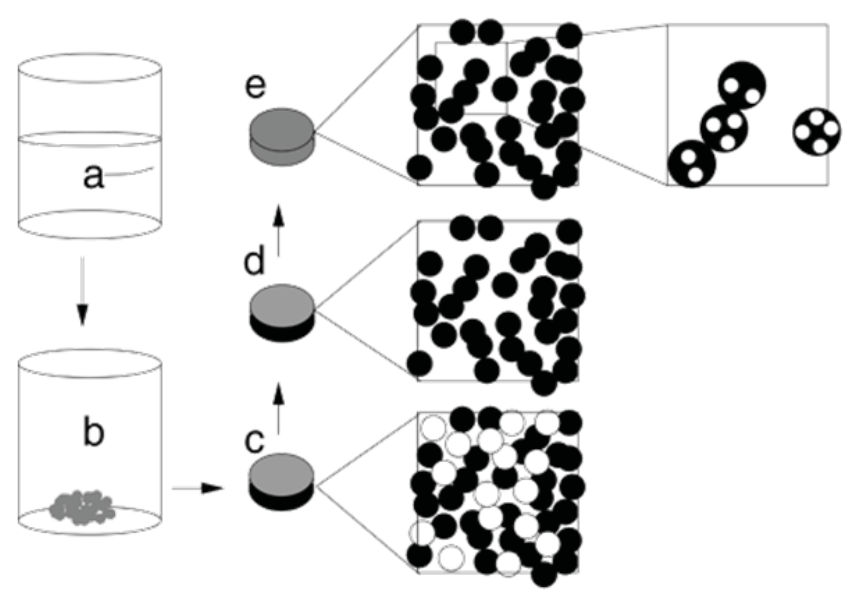

Fig. 15. Scheme for the generation of macroporous materials starting with the combustion synthetic preparation of an intimate mixture of two metal oxides [288].

form a macroporous NiO monolith (Fig. 15d). Reduction of this $\mathrm{NiO}$ monolith in $\mathrm{H}_{2} / \mathrm{Ar}$ should yield macroporous Ni metal (Fig. 15e). The $\mathrm{ZnO}$ particles which are thrown out of the Ni matrix result, inadvertently, in another, smaller level of porosity (Fig. 15f). Such selective leaching enables adjustment in the hierarchical porosity by tuning the starting phase ratio, particle diameter, and available leaching strategies. For example, Toberer et al. [289] demonstrated the formation of porous $\mathrm{Ni}_{0.7 \mathrm{Zn} 0.3 \mathrm{O}}$ monoliths starting from a single-source $\mathrm{Ni}-\mathrm{Zn}$ oxalate by decomposing it to the oxides, followed by selective leaching of ZnO. Reduction of porous $\mathrm{Ni}_{0.7} \mathrm{Zn}_{0.3} \mathrm{O}$ in $\mathrm{H}_{2} / \mathrm{N}_{2}$ yielded a $\mathrm{Ni}$ monolith which retained the open pore structure of the oxide intermediate. The porous $\mathrm{Ni}_{0.7} \mathrm{Zn}_{0.3} \mathrm{O}$ displayed significant macroporosity, with a continuous network of pores that were 1-3 $\mu \mathrm{m}$ in diameter. The $\mathrm{Ni}_{0.7} \mathrm{Zn}_{0.3} \mathrm{O}$ grains were well-faceted as they had not been reheated following the leaching process, and there was good connectivity between the grains. In a similar vein, decomposing the $\mathrm{Fe}-\mathrm{Zn}$ oxalate $\mathrm{Fe}_{0.5} \mathrm{Zn}_{0.5} \mathrm{C}_{2} \mathrm{O}_{4} \cdot 2 \mathrm{H}_{2} \mathrm{O}$ gives an intimate mixture of spinel $\mathrm{ZnFe}_{2} \mathrm{O}_{4}$ and $\mathrm{ZnO}$, from which removal of $\mathrm{ZnO}$ results in a porous $\mathrm{ZnFe}_{2} \mathrm{O}_{4}$ monolith [289]. On the basis of this method, they developed a route to hierarchically porous rutile titania that prevented the need for preformed or preassembled structure-directing agents by a preparation process that involved the successive leaching of phases and components from a dense composite of wurtzite $\mathrm{ZnO}$ and inverse spinel $\mathrm{Zn}_{2} \mathrm{TiO}_{4}$ [290]. The resulting monoliths were composed of grains of highly crystalline rutile titania and possessed a hierarchy of interconnected pores with length scales of 2-5 $\mu \mathrm{m}$ and 100-200 $\mathrm{nm}$ in diameter. Furthermore, they have developed a novel strategy for the preparation of hierarchically porous materials using volume loss that occurred on reduction of the metal and involved temperatures at which the pores that form did not rapidly close [291]. They described the formation of hierarchically porous $\mathrm{MnO}$ by a process of reduction of sintered pellets of $\mathrm{Mn}_{3} \mathrm{O}_{4}$, with pore formation being induced by volume loss. Significantly, the mesopore formation is cyclable, oxidizing the final $\mathrm{MnO}$ material resulted in closing of the mesopores without the macropore morphology being altered.
$\mathrm{Mn}_{3} \mathrm{O}_{4}$ pellets reduced to $\mathrm{MnO}$ retain the macropore network and grain connectivity. Additionally, the inherent volume loss during the phase change results in mesopores penetrating into the macropore walls. The macropores are $1 \mathrm{~mm}$ in diameter, and the mesopores are $50 \mathrm{~nm}$ across. Interestingly, the process of mesopore formation was regenerative as well, with mesopores in the $50 \mathrm{~nm}$ size range forming upon reduction, closing over upon reoxidation, and forming again upon reduction. Such mesopore regeneration may prove to be useful in high-temperature applications. It can be concluded that the selective-leaching processes can be controlled to give rise to unusual hierarchically porous architectures. The resulting porous monoliths have led to conformal coatings, porous metals, and hierarchically porous structures. It is worth noting that the formation of mesoporous single crystals through phase-changes and vapor-phase leaching of a sacrificial element is extremely intriguing. As these approaches are quite general, it is desired that this selective leaching process inspires further investigations into the formation of various materials with porous hierarchy.

\subsection{Hierarchically porous carbon-based catalysts}

Porous carbon materials have attracted much attention and have been applied in many fields due to their appealing physical properties, such as low density, high corrosion resistance, tailorable surface properties, tunable porosities, and excellent thermal and mechanical stability [292-295]. Importantly, porous carbons have been successfully used as efficient metal-catalyst supports in heterogeneous catalysis, particularly as precious-metal catalysts for organic reactions [296,297]. Recently, many efforts have been made to develop metal-/metal oxide-supported on porous carbons to form porous carbon-based catalysts [296,297]. It has been pointed out that surface area and pore size distribution are the key factors for the success of porous carbon-based catalysts. Therefore, comparing the catalytic performance of carbon-based supports with high surface areas and different pore architectures remains a challenge. Hierarchically porous carbons used as supports have attracted much attention due to their very high surface area and hierarchical porosity. Many methodologies have been developed to fabricate hierarchically porous carbons, such as chemical vapour deposition method, the use of a hierarchically porous scaffold (and/or sacrificial template) and in situ carbonization procedures. In this part, we will summarize some representative examples to introduce the main synthetic methods for the preparation of hierarchically porous carbons in combination with their application as catalyst supports.

\subsubsection{Templating methods}

Yu et al. [298,299] demonstrated the fabrication of macrostructurally patterned, highly ordered, three-dimensionally interconnected, porous carbons with uniform mesoporous walls by template replication of the aggregation of small silica particles, which were themselves templated by a self-assembled, ordered lattice of larger, monodisperse poly-styrene spheres used as moulds. The bimodal porosity 


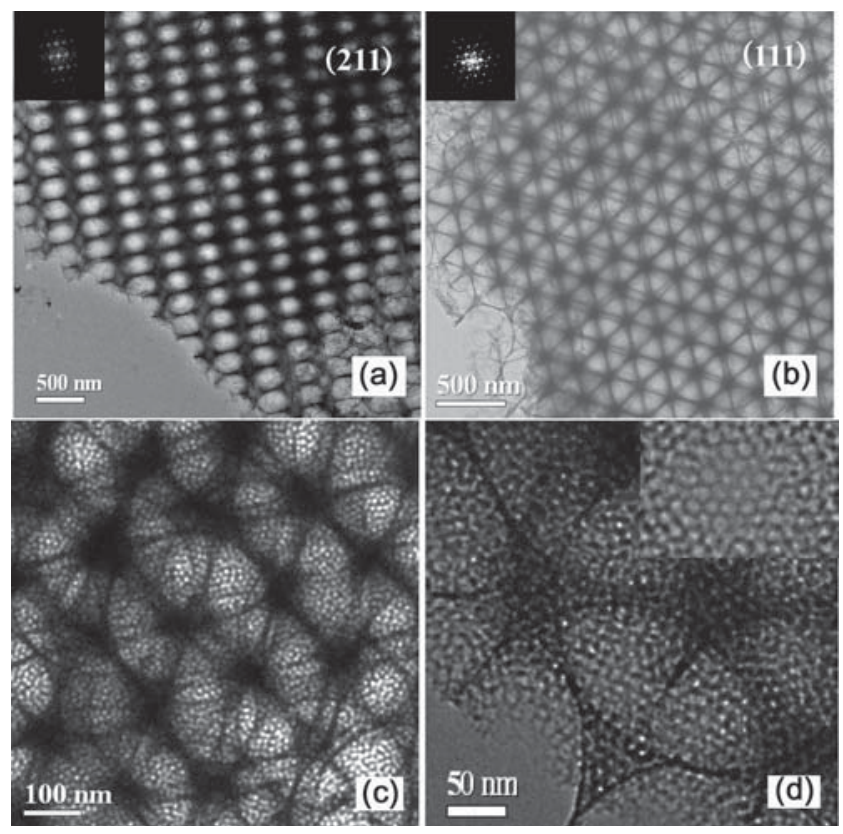

Fig. 16. TEM images of ordered macro-/mesoporous carbons with macropore arrays viewed from (211) (a) and (111) (b), respectively. (c, d) High-magnification TEM images showing the carbon mesostructure [301].

could easily be manipulated by controlling the size of the polystyrene and silica particles. Woo et al. [300] reported the preparation of three dimensionally ordered macroporous (3DOM) carbons with mesoporous walls by a colloidal crystal templating method. Monodisperse polystyrene (PS) latex and colloidal silica were used as macropore and mesopore templates, respectively. Furthermore, PS spheres were also used as carbon sources during the carbonization process. Deng et al. [301] demonstrated a facile dual-templating approach to prepare hierarchically ordered macro-/mesoporous carbons (Fig. 16). In this work, monodisperse silica colloidal crystals were used as a hard template and amphiphilic triblock co-polymer PEO-PPO-PEO as a soft template. The resultant porous carbons presented a highly ordered face-centered cubic macrostructure with tunable pore size of 230-430 nm and interconnected windows with a size of 30-65 nm (Fig. 16). Very recently, Zhang et al. [302] reported a novel in situ self-assembly strategy of colloidal polymer and silica spheres to prepare hierarchically ordered porous carbons with interconnected macropores and mesopores. In this work, colloidal polymer spheres were first blended with colloidal silica and then with sucrose and sulfuric acid to obtain a stable dispersion. Then, this dispersion was cast on a glass substrate. A hierarchically ordered porous carbon could be directly obtained by etching in HF solution to remove silica. Significantly, this bimodally porous carbon when used as a support can greatly increase the catalytic activity of a Pt-Ru catalyst.

\subsubsection{Replicating methods}

Replicating methods have been developed to fabricate hierarchically porous carbon via a replication of a hierarchically porous structure. Various hierarchically porous materials have been used as hard templates for the formation of hierarchically porous carbons by replication. For example, Lee et al. [303306] reported the preparation of new mesocellular carbon foams through the carbonization of phenol-resin inside the pores of mesocellular aluminosilicate foam templates. The new mesocellular carbon with bimodal mesoporous systems exhibited a very high BET surface area of $1037 \mathrm{~m}^{2} / \mathrm{g}$ and large pore volume of $1.66 \mathrm{~m}^{3} / \mathrm{g}$. Furthermore, they [305] synthesized a hierarchically bimodal mesoporous carbon material using bimodal mesoporous silica as a hard template by a replication process. The resultant bimodal mesoporous carbons presented $4 \mathrm{~nm}$ sized framework mesopores and $\sim 30 \mathrm{~nm}$ size textural pores. In addition, hierarchically meso-macroporous silicas have been used as hard-templates to fabricate hierarchically porous carbons with meso-macroporous structure by replication [307,308]. Monolithic, meso-macroporous carbon with a fully interconnected hierarchical pore structure was successfully prepared through a replication of meso-macroporous silica, where the macropore diameter could be varied between 0.5-30 $\mu \mathrm{m}$ in a controlled manner [307]. Hierarchically meso-macroporous carbons with different morphologies, including rods, tablets and membranes were obtained by tuning the initial meso-macroporous silica templates.

Very recently, hierarchically meso-macroporous carbon materials were successfully prepared by using a replication of mesoporous walls of a meso-macroporous zirconia exotemplate [255]. The resultant hierarchically porous carbons possessed funnel shaped straight macrochannels, parallel to each other and perpendicular to the tangent of the particles' dense mesoporous shell. A high surface area of $955 \mathrm{~m}^{2} / \mathrm{g}$ with a mesopore volume of $0.44 \mathrm{~cm}^{3} / \mathrm{g}$ was obtained. Hyeon et al. [309-310] demonstrated the preparation of carbon capsules with hollow core/mesoporous shell (HCMS) structures using submicrometer-size solid core/mesoporous shell (SCMS) silica spheres as templates. Here, the resultant structure of the HCMS carbon capsules was an inverse replica of the SCMS silica sphere templates. In addition, nonspherical pseudohexagonal prismatic carbons with hollow core/mesoporous shell structures were prepared through a replication process by employing the bimodal porous silicate with a zeolite core/mesoporous shell as a template [311].

\subsubsection{Chemical vapour deposition}

Song et al. [312] reported on novel carbon nanoparticles constructed from a mesoporous core and microporous shell in a one-step process that was based on detonation-assisted chemical vapor deposition (Fig. 17). The mesoporous walls consisted of a few graphene layers and could be controllably removed by a wetting oxidation treatment, leaving behind hollow nanoparticles. They have explored the catalytic dehydrogenation of cyclohexane to benzene using this core-shell carbon nanoparticles supported platinum catalyst (Fig. 17(b)). This porous core-shell nanostructure provided ideal short pores which were superior to active carbon and carbon nanotubes with long channels, resulting in an enhancement in the diffusion of guest molecules. The resultant catalyst exhibited a very high and stable catalytic performance during the dehydrogena- 

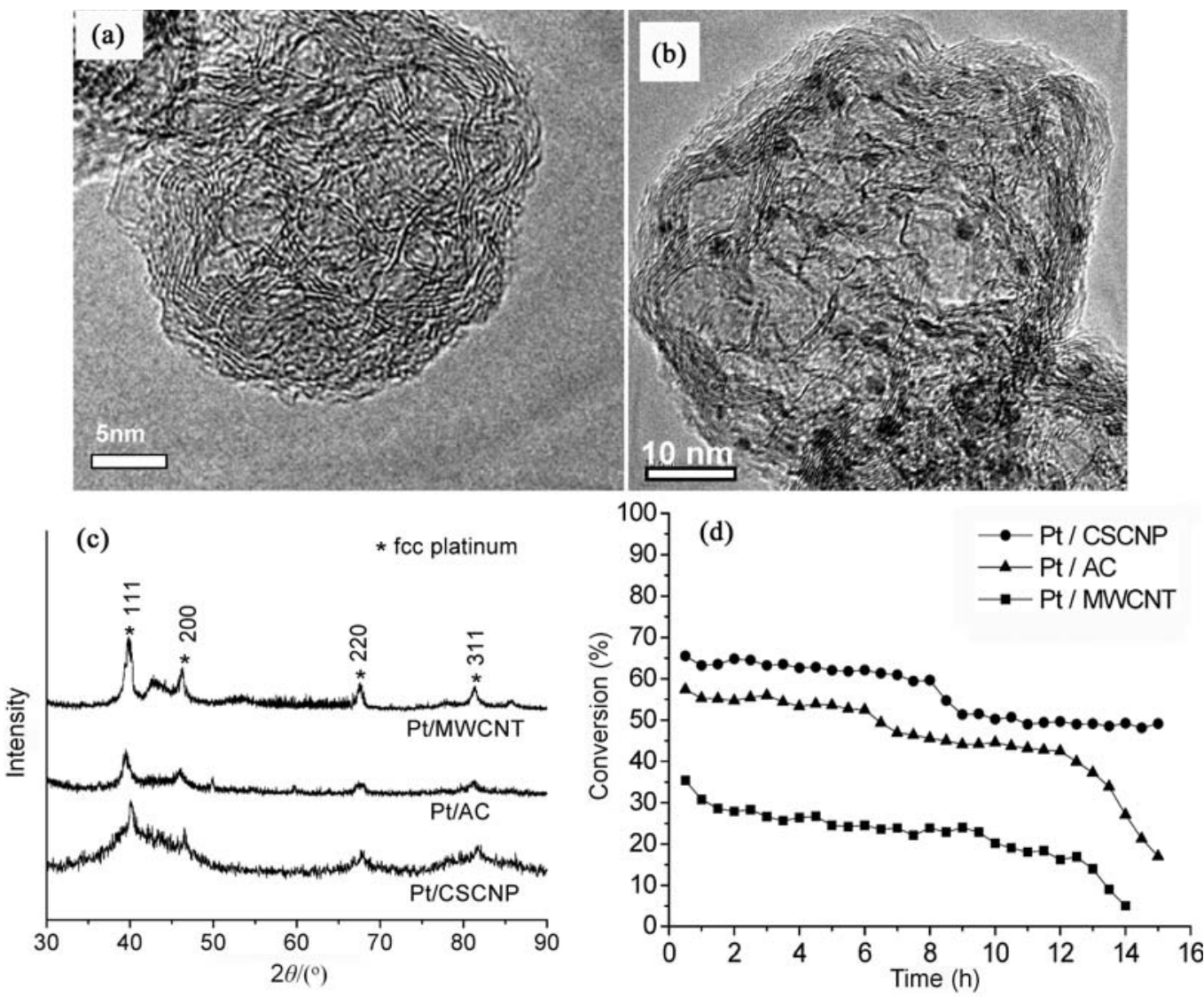

Fig. 17. TEM images of CSCNP (a) and Pt/CSCNP (b); X-ray diffraction patterns of the Pt/MWCNT, Pt/AC, and Pt/CSCNP catalysts (c); Cyclohexane conversions over Pt/CSCNP, Pt/AC, and Pt/MWCNT catalysts as a function of reaction duration (d) [312].

tion of cyclohexane, which was much higher than that of active carbon and carbon nanotubes (Fig. 17(c) and (d)).

\section{Conclusions and prospect}

Over the years, hierarchically porous catalysts have attracted continuously increasing interest and methods for their preparation have been successfully developed. Here, the aim was to provide a detailed overview concerning the recent developments that have been achieved in the synthesis strategies and catalytic performances exhibited by the resultant hierarchically porous catalysts. In this contribution, three different types of hierarchically porous catalysts were distinguished according to their composition from hierarchically porous zeolites, hierarchically porous metal oxides, and hierarchically porous carbon-based catalysts. The available approaches with representative examples in more details for each kind of hierarchically porous catalysts were illustrated.

Hierarchically porous catalysts, led by hierarchically porous zeolites, have been applied in various organic catalytic reactions. It has proven that the catalytic performances of hierarchically porous catalysts can be improved in the presence of multiple level of porosity due to significantly enhanced mass transport. However, it could be argued that the hierarchically porous structure cannot easily be designed and synthesized. The optimal design of hierarchically porous catalysts requires the generation of multiple levels of porosities being appropri- ately connected in ordered to maximize the benefits of hierarchy in catalyzed reactions. Moreover, up to now, direct evidence of the diffusion characteristics to enhance mass transport has not fully been provided. Consequently, the synthesis and catalytic application of hierarchically porous materials should be conducted with accompanying diffusion studies in the future. In addition, the location of catalytic active functionalities at the right porosity scale is not easy to achieve either.

To date, many of the available approaches for the formation of hierarchically porous catalysts have been confined to the laboratory scale and are cost prohibitive as well. Pérez-Ramírez's group [313] demonstrated the experience in large scale hierarchically mesoporous zeolite granules synthesis and modification resulted from the $1.5 \mathrm{~m}^{3}$ reactor, which can be reliably extrapolated to the plant scale. This work paves the way for various applications of hierarchically structured zeolite catalysts towards industrial realization. It is of urgent necessity to demonstrate their large-scale preparation in order to truly ascertain future perspectives for hierarchically porous catalysts as technical catalysts.

The interest in developing various multiporous catalysts by more novel strategies is great, as the desire for hierarchical porous structures with special functionalities is high. These advanced materials also demonstrated their superiority in energy [314] and environmental [315] applications. Therefore, an effort to develop exciting hierarchically porous catalysts with novel hierarchically porous structures and studies on their 
applications in catalysis will continue to attract increasing attention during the years to come.

\section{Acknowledgements}

Bao-Lian Su thanks the Chinese Central Government for an "Expert of the State" position in the program of "Thousand talents", the Chinese Ministry of Education for a "Changjiang" Chair Professor position located at Wuhan University of Technology and Clare Hall College and the Department of Chemistry at the University of Cambridge for a Clare Hall visiting fellow and financial support.

\section{References}

[1] Imhof A, Pine D J. Nature, 1997, 389: 948

[2] Schacht S, Huo Q, VoigtMartin I, Stucky G, Schüth F. Science, 1996, 273: 768

[3] Zhao D, Yang P, Chmelka B F, Stucky G D. Chem Mater, 1999, 11: 1174

[4] Ryoo R, Ko C H, Kruk M, Antochshuk V, Jaroniec M. J Phys Chem B, 2000, 104: 11465

[5] Yuan Z Y, Blin J L, Su B L. Chem Commun, 2002: 504

[6] Fratzl P.J R Soc Interface, 2007, 4: 637

[7] Lakes R. Nature, 1993, 361: 511

[8] Kim S S, Shah H, Pinnavaia T J. Chem Mater, 2003, 15: 1664

[9] Sanchez C, Arribart H, Medeleine M, Guille G. Nat Mater, 2005, 4: 277

[10] Corma A. Chem Rev, 1997, 97: 2373

[11] Clark J H. Acc Chem Res, 2002, 35: 791

[12] Su B L, Sanchez C, Yang X Y. Hierarchically Structured Porous Materials: From Nanoscience to Catalysis, Bomedicine, Optics and Energy. Germany: Wiley-VCH, 2012

[13] Parlett C M A, Wilson K, Lee A F. Chem Soc Rev, 2012, DOI: $10.1039 / \mathrm{c} 2 \mathrm{cs} 35378 \mathrm{~d}$

[14] Yuan Z Y, Su B L. J Mater Chem, 2006, 16: 663

[15] Chen L H, Li X Y, Zhang Y H, Yang X Y, Tang Y, Xiao F S, Su B L. J Mater Chem, 2012, 22: 17381

[16] Fratzl P, Weinkamer R. Prog Mater Sci, 2007, 52: 1263

[17] Lopez-Orozco S, Inayat A, Schwab A, Selvam T, Schwieger W. Adv Mater, 2011, 23: 2602

[18] Yang X Y, Léonard A, Lemaire A, Tian G, Su B L. Chem Commun, 2011, 47: 2763

[19] Serrano D P, Escola J M, Pizarro P. Chem Soc Rev, 2012, DOI: $10.1039 / \mathrm{c} 2 \mathrm{cs} 35330 \mathrm{j}$

[20] Ivanova I I, Knyazeva E E. Chem Soc Rev, 2012, DOI: $10.1039 / \mathrm{c} 2 \mathrm{cs} 3541 \mathrm{e}$

[21] Petkovich N D, Stein A. Chem Soc Rev, 2012, DOI: $10.1039 / \mathrm{c} 2 \mathrm{cs} 35308 \mathrm{c}$

[22] Cundy C S, Cox P A. Chem Rev, 2003, 103: 663

[23] International Zeolite Association. http://www.iza structure.org/

[24] Corma A. Chem Rev, 1995, 95: 559

[25] Corma A. J Catal, 2003, 216: 298

[26] Kresge C T, Leonowicz M E, Roth W J, Vartuli J C, Beck J S. Nature, 1992, 359: 710

[27] Inagaki S, Fukushima Y, Kuroda K. J Chem Soc, Chem Commun, 1993: 680

[28] Zhao D Y, Feng J L, Huo Q S, Melosh N, Frwdrickson G H, Chmelka B F, Stucky G D. Science, 1998, 279: 548

[29] Holland B T, Blanford C F, Stein A. Science, 1998, 281: 538

[30] Takahashi R, Sato S, Sodesawa T, Ara K, Yabuki M. J Catal, 2005,
229: 24

[31] Ogura M. Catal Surv Asia, 2008, 12: 16

[32] Louis B, Ocampo F, Yun H S, Twssonnier J P, Pereira M M. Chem Eng J, 2010, 161: 397

[33] Fang Y M, Hu H Q. J Am Chem Soc, 2006, 128: 10636

[34] Fan W, Snyder M A, Kumar S, Lee P S, Yoo W C, McCormick A V, Penn R L, Stein A, Tsapatsis M. Nat Mater, 2008, 7: 984

[35] Chen H Y, Wydra J, Zhang X Y, Lee P S, Wang Z P, Fan W, Tsapatsis M. J Am Chem Soc, 2011, 133: 12390

[36] Jacobsen C J H, Madsen C, Houzvicka J, Schemidt I, Carlsson A. J Am Chem Soc, 2000, 122: 7116

[37] Wei X, Smirniotis P G. Microporous Mesoporous Mater, 2006, 89: 170

[38] Kustova M Y, Hasselriis P, Christensen C H. Catal Lett, 2004, 96: 205

[39] Boisen A, Schmidt I, Carlsson A, Dahl S, Brorson M, Jacobsen C J H. Chem Commun, 2003: 958

[40] Janssen A H, Schmidt I, Jacobsen C J H, Koster A J, de Jong K P. Microporous Mesoporous Mater, 2003, 65: 59

[41] Yang Z X, Xia Y D, Mokaya R. Adv Mater, 2004, 16: 727

[42] Li H C, Sakamoto Y, Liu Z, Ohsuma T, Terasaki O, Tommes M, Che S N. Microporous Mesoporous Mater, 2007, 106: 174

[43] Cho S I, Choi S D, Kim J H, Kim G J. Adv Funct Mater, 2004, 14: 49

[44] Sakthivel A, Huang S J, Chen W H, Lan Z H, Chen K H, Kim T W, Ryoo R, Chiang A S T, Liu S B. Chem Mater, 2004, 16: 3168

[45] Sun C, Du J M, Liu J, Yang Y S, Ren N, Shen W, Xu H L, Tang Y. Chem Commun, 2010, 46: 2671

[46] Chu N B, Wang J Q, Zhang Y, Yang J H, LU J M, Yin D H. Chem Mater, 2010, 22: 2757

[47] Valtchev V, Schoeman B J, Hedlund J, Mintova S, Sterte J. Zeolites, 1996, 17: 408

[48] Wang Y J, Tang Y, Wang X D, Yang A W L, Gao Z. Chem Lett, 2000, 29: 1344

[49] García-Martínez J, Cazorla-Amorós D, Linares-Solano A, Lin Y S. Microporous Mesoporous Mater, 2001, 42: 255

[50] Ke C, Ni Z, Yang W, Wang Y J, Tang Y, Gu Y, Gao Z, Yang W L. Chem Commun, 2001: 783

[51] Schmidt I, Boisen A, Gustavsson E, Ståhl K, Pehrson S, Dahl S, Carlsson A, Jacobsen C J H. Chem Mater, 2001, 13: 4416

[52] Ryoo R, Joo S H, Kruk M, Jaroniec M. Adv Mater, 2001, 13: 677

[53] Tao Y, Kanoh H, Kaneko K. J Am Chem Soc, 2003, 125: 6044

[54] Tao Y, Kanoh H, Kaneko K.J Phys Chem B, 2003, 107: 10974

[55] Tao Y, Endo M, Kaneko K. J Am Chem Soc, 2009, 131: 904

[56] Tao Y, Kanoh H, Kaneko K. Langmuir, 2005, 21: 504

[57] Kang Y J, Shan W, Wu J, Zhang Y H, Wang X Y, Yang W L, Tang Y. Chem Mater, 2006, 18: 1861

[58] Shi Y, Li X, Hu J K, Lu J H, Ma Y C, Zhang Y H, Tang Y. J Mater Chem, 2011, 21: 16223

[59] Wang X D, Yang W L, Tang Y, Wang Y J, Fu S K, Gao Z. Chem Commun, 2000: 2161

[60] Valtchev V, Mintova S. Microporous Mesoporous Mater, 2001, 43 : 41

[61] Yang W, Wang X, Tang Y, Wang Y, Ke C, Fu S K. J Macromol Sci, Part A, 2002, 39: 509

[62] Valtchev V. Chem Mater, 2002, 14: 956

[63] Valtchev V. Chem Mater, 2002, 14: 4371

[64] Holland B T, Abrams L, Stein A. J Am Chem Soc, 1999, 121: 4308

[65] Wang Y J, Tang Y, Ni Z, Hua W M, Yang W L, Wang X D, Tao W C, Gao Z. Chem Lett, 2000, 29: 510

[66] Huang L M, Wang Z B, Sun J Y, Miao L, Li Q Z, Yan Y S, Zhao D Y.J Am Chem Soc, 2000, 122: 3530

[67] Zhu G S, Qiu S L, Gao F F, Li D S, Li Y F, Wang R W, Gao B, Li B S, 
Guo Y H, Xu R R, Liu Z, Tetasaki O. J Mater Chem, 2001, 11: 1687

[68] Valtchev V.J Mater Chem, 2002, 12: 1914

[69] Zhou Y, Antonietti M. Chem Commun, 2003: 2564

[70] Rhodes K H, Davis S A, Caruso F, Zhang B J, Mann S. Chem Mater, 2000, 12: 2832

[71] Dong A, Wang Y, Tang Y, Ren N, Zhang Y H, Gao Z. Chem Mater, 2002, 14: 3217

[72] Dong A, Wang Y, Tang Y, Wang D J, Ren N, Zhang Y H, Gao Z. Chem Lett, 2003, 32: 790

[73] Shi J, Ren N, Zhang Y H, Tang Y. Microporous Mesoporous Mater, 2010, 132: 181

[74] Xiong C, Coutinho D, Balkus J K J. Microporous Mesoporous Mater, 2005, 86: 14

[75] Dong A, Ren N, Yang W, Wang Y, Zhang Y, Wang D, Hu J, Gao Z, Tang Y. Adv Funct Mater, 2003, 13: 943

[76] Dong A, Wang Y J, Tang Y, Zhang Y H, Ren N, Gao Z. Adv Mater, 2002, 14: 1506

[77] Thomas K R J, Lin J T, Velusamy M, Tao Y T, Chuen C H. Adv Funct Mater, 2004, 14: 83

[78] Dong A G, Wang Y J, Wang D J, Yang W L, Zhang Y H, Ren N, Gao Z, Tang Y. Microporous Mesoporous Mater, 2003, 64: 69

[79] Song W, Kanthasamy R, Grassian V, Larsen S C. Chem Commun, 2004: 1920

[80] Ren N, Yang Y H, Shen J, Zhang Y H, Xu H L, Gao Z, Tang Y.J Catal, 2007, 251: 182

[81] Ren N, Yang Y H, Zhang Y H, Wang Q R, Tang Y.J Catal, 2007, 246: 215

[82] Wang Y J, Caruso F. Adv Funct Mater, 2004, 14: 1012

[83] Wang L, Yin C, Shan Z, Liu S, Du Y, Xiao F S. Colloids Surf A, 2009, 340: 126

[84] Wang D J, Zhang Y H, Dong A G, Tang Y, Wang Y J, Xia J C, Ren N. Adv Funct Mater, 2003, 13: 563

[85] Wang D J, Tang Y, Dong A G, Zhang Y H. Acta Chim Sin, 2003, 61: 1425

[86] Qian L S, Tang K Z, Wang C L. Acta Chim Sin, 2003, 61: 1425

[87] Liu W W, Zeng C F, Zhang L X, Wang H T, Xu N P. Mater Chem Phys, 2007, 103: 508

[88] Valtchev V P, Smaihi M, Faust A C, Vidal L. Chem Mater, 2004, 16: 1350

[89] Zhu H B, Liu Z C, Wang Y D, Kong D J, Yuan X H, Xie Z K. Chem Mater, 2007, 20: 1134

[90] Xie Z K. Porous Catalytic Materials With New Structure And Improved Performance. Beijing: Sinopec Press, 2010

[91] Wang D J, Zhu G B, Zhang Y H, Yang W L, Wu B Y, Tang Y, Xie Z K. New J Chem, 2005, 29: 272

[92] Zhao J J, Hua Z L, Liu Z C, Li Y S, Guo L M, Bu W B, Cui X Z, Ruan M L, Chen H R, Shi J L. Chem Commun, 2009: 7578

[93] Yue M B, Sun L B, Zhuang T T, Dong X, Chun Y, Zhu J H. J Mater Chem, 2008, 18: 2044

[94] Gu F N, Wei F, Yang J Y, Lin N, Lin W G, Wang Y, Zhu J H. Chem Mater, 2010, 22: 2442

[95] Choi M, Cho H S, Srivastava R, Venkatesan C, Choi D H, Ryoo R. Nat Mater, 2006, 5: 718

[96] Choi M, Srivastava R, Ryoo R. Chem Commun, 2006: 4380

[97] Srivastava R, Choi M, Ryoo R. Chem Commun, 2006: 4489

[98] Shanbhag G V, Choi M, Kim J, Ryoo R. J Catal, 2009, 264: 88

[99] Cho K, Cho H S, De Menorval L C, Ryoo R. Chem Mater, 2009, 21: 5664

[100] Wang H, Pinnavaia T J. Angew Chem, Int Ed, 2006, 45: 7603

[101] Choi M, Na K, Kim J, Sakamoto Y, Terasaki O, Ryoo R. Nature, 2009, 461: 246

[102] Na K, Choi M, Park W, Sakamoto Y, Terasaki O, Ryoo R. J Am Chem
Soc, 2010, 132: 4169

[103] Na K, Jo C, Kim J, Cho K, Jung J, Seo Y, Messinger R J, Chmelka B F, Ryoo R. Science, 2011, 333: 328

[104] Xiao F S, Wang L F, Yin C Y, Lin K F, Di Y, Li J X, Xu R R, Su D S, Schlögl R, Yokoi T, Tatsumi T. Angew Chem, Int Ed, 2006, 118: 3162

[105] Wang L F, Zhang Z, Yin C Y, Shan Z, Xiao F S. Microporous Mesoporous Mater, 2010, 131: 58

[106] Liu S Z, Cao X J, Li L S, Li C J, Ji Y Y, Xiao F S. Colloids Surf A, 2008, 318: 269

[107] Song J W, Ren L M, Yin C Y,Ji Y Y, Wu Z F, Li J X, Xiao F S. J Phys Chem C, 2008, 112: 8609

[108] Liu F J, Willhammar T, Wang L, Zhu L F, Sun Q Meng X J, Carrillo-Cabrera W, Zou X D, Xiao F S. J Am Chem Soc 2012, 134: 4557

[109] Zhu H B, Liu Z C, Kong D J, Wang Y D, Xie Z K. J Phys Chem C, 2008, 112: 17257

[110] Tao Y S, Kanoh H, Abrams L, Kaneko K. Chem Rev, 2006, 106: 896

[111] Van Donk S, Janssen A H, Bitter J H, De Jong K P. Catal Rev, 2003, 45: 297

[112] Marcilly C. Acido-Basic Catalysis: Application to Refining and Petrochemistry. Editions Ophrys, 2006

[113] Chal R, Gérardin C, Bulut M, Van Donk S. ChemCatChem, 2011, 3: 67

[114] Xiao F S. Acta Petrol Sin, 2006, 22: 9

[115] Matsukata M, Ogura M, Osaki T, Raja P, Rao H D, Nomura M, Kikuchi E. Topics Catal, 1999, 9: 77

[116] Wang J, Groen J C, Yue W B, Zhou W Z, Coopens M O. Chem Commun, 2007: 4653

[117] Zhou J, Hua Z L, Shi J L,He Q J, Guo L M, Ruan M L. Chem Eur J, 2009, 15: 12949

[118] Zhou J, Hua Z L, Cui X Z, Ye Z Q, Cui F M, Shi J L. Chem Commun, 2010, 46: 4994

[119] Ogura M, Shinomiya S, Tateno J, Nara Y, Nomura M, Kikuchi E, Matsukata M. Appl Catal A, 2001, 219: 33

[120] Groen J C, Peffer L A A, Moulijn J A, Pérez-Ramírez J. Microporous Mesoporous Mater, 2004, 69: 29

[121] Groen J C, Peffer L A A, Moulijn J A, Pérez-Ramírez J. Chem Eur J, 2005, 11: 4983

[122] Groen J C, Abelló S, Villaescusa L A,Pérez-Ramírez J. Microporous Mesoporous Mater, 2008, 114: 93

[123] Wei X, Smirniotis P G. Microporous Mesoporous Mater, 2006, 97: 97

[124] Paixão V, Carvalho A P, Rocha J, Fernandes A, Martins A. Microporous Mesoporous Mater, 2010, 131: 350

[125] Bonilla A, Baudouin D, Pérez-Ramírez J.J Catal, 2009, 265: 170

[126] Van Miltenburg A, Pawlesa J, Bouzga A M, Žilková N,Čejka J, Stöcker M. Topics Catal, 2009, 52: 1190

[127] Verboekend D, Villaescusa L A, Thomas K, Stan A, Pérez-Ramírez J. Catal Today, 2010, 152: 11

[128] Verboekend D, Pérez-Ramírez J. Chem Eur J, 2011, 17: 1137

[129] Su L L, Liu L, Zhuang J Q, Wang H X, Li Y G, Shen W J, Xu Y D, Bao X H. Catal Lett, 2003, 91: 155

[130] Mei C S, Liu Z C, Wen P Y, Xie Z K, Hua W M, Gao Z. J Mater Chem, 2008, 18: 3496

[131] Wang Y, Tuel A. Microporous Mesoporous Mater, 2008, 113: 286

[132] Van Der Puil N, Dautzenberg F, Van Bekkum H, Jansen J C. Microporous Mesoporous Mater, 1999, 27: 95

[133] Shan Z, Van Kooten W, Oudshoorn O, Jansen J C,van Bekkum H, van den Bleek C M, Cails H P A. Microporous Mesoporous Mater, 2000, 34: 81

[134] Guan N J, Han Y S. Chem Lett, 2000: 1084 
[135] Seijger G B F, Van Den Berg A, Riva R, Krishna K, Calis H P A, van Bekkum H. Appl Catal A, 2002, 236: 187

[136] Seijger G B F, Oudshoorn O L, Van Kooten W E J, Jansen J C, van Bekkum H, van den Bleek C M, Calis H P A. Microporous Mesoporous Mater, 2000, 39: 195

[137] Zampieri A, Colombo P, Mabande G T P, Selvam T, Schwleger W, Scheffler F. Adv Mater, 2004, 16: 819

[138] Scheffler F, Zampieri A, Schwieger W, Zeschy J, Scheffler M, Greil P. Adv Appl Ceram, 2005, 104: 43

[139] Wang Y J, Tang Y, Wang X D, Dong A G, Shan W, Gao Z. Chem Lett, 2001, 30: 1118

[140] Wang Z Y, Al-Daous M A, Kiesel E R, Li F, Stein A. Microporous Mesoporous Mater, 2009, 120: 351

[141] Zhang B J, Davis S A, Mendelson N H, Mann S. Chem Commun, 2000: 781

[142] Zhang B J, Davis S A, Mann S. Chem Mater, 2002, 14: 1369

[143] Lei Q, Zhao T B, Li F Y, Wang Y F, Hou L L. J Porous Mater, 2008, 15: 643

[144] Dong A, Wang Y, Tang Y, Ren N, Zhang Y, Yue Y, Gao Z. Adv Mater, 2002, 14: 926

[145] Wang Y J, Tang Y, Dong A G, Wang X D, Ren N, Shan W, Gao Z. Adv Mater, 2002, 14: 994

[146] Zampieri A, Mabande G T P, Selvam T, Schwieger W, Rudolph A, Hermann R, Sieber H, Greil P. Mater Sci Eng C, 2006, 26: 130

[147] Valtchev V, Gao F, Tosheva L. New J Chem, 2008, 32: 1331

[148] Komarneni S, Katsuki H, Furuta S. J Mater Chem, 1998, 8: 2327

[149] Anderson M W, Holmes S M, Hanif N, Cundy C S. Angew Chem, Int $E d, 2000,39: 2707$

[150] Wang Y J, Tang Y, Dong A G, Wang X D, Ren N, Gao Z.J Mater Chem, 2002, 12: 1812

[151] Zampieri A, Sieber H, Selvam T, Mabande G T P, Schwieger W, Scheffler F, Scheffler M, Greil P. Adv Mater, 2005, 17: 344

[152] Zampieri A, Kullmann S, Selvam T, Bauer J, Schwieger W, Sieber H, Fey T, Greil P. Microporous Mesoporous Mater, 2006, 90: 162

[153] Johnson C D, Worrall F. J Mater Chem, 2007, 17: 476

[154] Dong W Y, Sun Y J, He H Y, Long Y C. Microporous Mesoporous Mater, 1999, 32: 93

[155] Dong W Y, Qiu X P, Ren Y, Long Y C. Chem Lett, 2002, 31: 374

[156] Shimizu S, Hamada H. Adv Mater, 2000, 12: 1332

[157] Scheffler F, Schwieger W, Freude D, Liu H, Heyer W, Janowski F. Microporous Mesoporous Mater, 2002, 55: 181

[158] Rauscher M, Selvam T, Schwieger W, Freude D. Microporous Mesoporous Mater, 2004, 75: 195

[159] Wang H T, Huang L M, Wang Z B, Mitra A, Yan Y S. Chem Commun, 2001: 1364

[160] Lei Q, Zhao T B, Li F Y, Wang Y, Zheng M F. Chem Lett, 2006, 35 : 490

[161] Lei Q, Zhao T B, Li F Y, Zhang L L, Wang Y. Chem Commun, 2006: 1769

[162] Zhao T B, Xu X, Tong Y C, Lei Q Li F Y, Zhang L L. Catal Lett, 2010, 136: 266

[163] Sachse A, Galarneau A, Di Renzo F, Fajula F, Coq B. Chem Mater, 2010, 22: 4123

[164] Özcan A, Kalipçilar H. Ind Eng Chem Res, 2006, 45: 4977

[165] Xu X, Zhao T B, Qi J, Guo Y T, Miao C, Li F Y, Liang M. Mater Lett, 2010, 64: 1660

[166] Wang D J, Liu Z N, Wang H, Xie Z K, Tang Y. Microporous Mesoporous Mater, 2010, 132: 428

[167] Yang H Q, Liu Z C, Gao H X, Xie Z K. J Mater Chem, 2010, 20: 3227

[168] Yang X Y, Tian G, Chen L H, Li Y, Rooke J C, Wei Y X, Liu Z M, Deng Z, Van Tendeloo Gustaaf, Su B L. Chem Eur J, 2011, 17: 14987

[169] Chen L H, Li X Y, Tian G, Li Y, Tan H Y, Van Tendeloo G, Zhu G S,
Qiu S L, Yang X Y, Su B L. ChemSusChem, 2011, 4: 1452

[170] Chen L H, Xu S T, Li X Y, Tian G, Li Y, Rookie J C, Zhu G S, Qiu S L, Wei Y X, Yang X Y, Liu Z M, Su B L. J Colloid Interf Sci, 2012, 377: 368

[171] Sasaki M, Song C, Plummer M A. Fuel, 2000, 79: 295

[172] Cooper B H, Donnis B L. Appl Catal A, 1996, 137: 203

[173] Song C S, Ma X L. Appl Catal B, 2003, 41: 207

[174] Egorova M, Prins R. J Catal, 2004, 224: 278

[175] Song C, Schmitz A D. Energy Fuels, 1997, 11: 656

[176] Yasuda H, Matsubayashi N, Sato T, Yoshimura Y. Catal Lett, 1998, 54: 23

[177] Yasuda H, Sato T, Yoshimura Y. Catal Today, 1999, 50: 63

[178] Pawelec B, Mariscal R, Navarro R M, van Bokhorst S, Rojas S, Fierro J L G. Appl Catal A, 2002, 225: 223

[179] Miller J T, Koningsberger D C. J Catal, 1996, 162: 209

[180] Tang T D, Yin C Y, Wang L F, Ji Y Y, Xiao F S.J Catal, 2007, 249: 111

[181] Tang T D, Yin C Y, Wang L F, Ji Y Y, Xiao F S. J Catal, 2008, 257: 125

[182] Sun Y Y, Prins R. Angew Chem, Int Ed, 2008, 47: 8478

[183] Christensen C H, Schmidt I, Carlsson A, Johannsen K, Herbst K. J Am Chem Soc, 2005, 127: 8098

[184] Kang J C, Cheng K, Zhang L, Zhang Q H, Ding J S, Hua W Q, Lou Y C, Zhai Q G, Wang Y. Angew Chem, Int Ed, 2011, 50: 5200

[185] Cheng K, Kang J C, Huang S W, You Z Y, Zhang Q H, Ding J S, Hua W Q, Lou Y C, Deng W P, Wang Y. ACS Catal, 2012, 2: 441

[186] Jin M J, Taher A, Kang H J, Choi M, Ryoo R. Green Chem, 2009, 11: 309

[187] Choi M, Lee D H, Na K, Yu B W, Ryoo R. Angew Chem, Int Ed, 2009, 48: 3673

[188] Stanislaus A, Cooper B H. Catal Rev Sci Eng, 1994, 36: 75

[189] Sachtler WMH, Stakheev AY. Catal Today, 1992, 12: 283

[190] Taramasso M, Manara G, Fattore V, Notari B. US 4410501. 1983

[191] Taramasso M, Manara G, Fattore V, Notari B. US 4666692. 1987

[192] Tatsumi T, Nakamura M, Negishi S, Tominaga H. Chem Commun, 1990: 476

[193] Notari B. Adv Catal, 1996, 41: 253

[194] Clerici M G, Ingallina P. J Catal, 1993, 140: 71

[195] Bellussi G, Rigutto M S. Stud Surf Sci Catal, 1994, 85: 177

[196] Ratnasamy P, Srinivas D, Knozinger H. Adv Catal, 2004, 48: 1

[197] Bhaumik A, Kumar R. J Chem Soc, Chem Commun, 1995: 349

[198] Bhaumik A, Samanta S, Mal N. Microporous Mesoporous Mater, 2004, 68: 29

[199] Zhang H, Liu Y, Jiao Z, He M, Wu P. Ind Eng Chem Res, 2009, 48: 4334

[200] van der Pol A J H P, Verduyn A J, van Hooff J H C. Appl Catal A, 1992, 92: 113

[201] Tuel A, Ben Tâarit Y. Appl Catal A, 1993, 102: 69

[202] Schmidt I, Krogh A, Wienberg K, Carlsson A, Brorson M, Jacobsen C J H. Chem Commun, 2000: 2157

[203] Lee Y J, Lee J S, Park Y S, Yoon K B. Adv Mater, 2001, 13: 1259

[204] Ke X, Xu L, Zeng C, Zhang L, Xu N. Microporous Mesoporous Mater, 2007, 106: 68

[205] Fang Y, Hu H. Catal Commun, 2007, 8: 817

[206] Wang Y, Lin M, Tuel A. Microporous Mesoporous Mater, 2007, 102: 80

[207] Cheneviere Y, Chieux F, Caps V, Tuel A. J Catal, 2010, 269: 161

[208] Serrano D, Sanz R, Pizarro P, Moreno I. Chem Commun, 2009: 1407

[209] Xin H C, Zhao J, Xu S T, Li J P, Zhang W P, Guo X W, Hensen E J M, Yang Q H, Li C. J Phys Chem C, 2010, 114: 6553

[210] Chen L H, Li X Y, Tian G, Li Y, Rookie J C, Zhu G S, Qiu S L,Yang X Y, Su B L. Angew Chem, Int Ed, 2011, 50: 11156

[211] Drisko G L, Luca V, Sizgek E, Scales N, Caruso R A. Langmuir, 2009, 
25: 5286

[212] Blanford C F, Yan H, Schroden R C, Al-Daous M, Stein A. Adv Mater, 2001, 13: 401

[213] Tosheva L,Valtchev V P. Chem Mater, 2005, 17: 2494

[214] Stein A. Adv Mater, 2003, 15: 763

[215] Taguchi A, Schüth F. Microporous Mesoporous Mater, 2005, 77: 1

[216] Schüth F. Chem Mater, 2001, 13: 3184

[217] Scott B J, Wirnsberger G, Stucky G D. Chem Mater, 2001, 13: 3140

[218] Sanchez C, Lebeau B, Chaput F, Boilot J P. Adv Mater, 2003, 15: 1969

[219] Smatt J H, Weidenthaler C, Rosenholm J B, Linden M. Chem Mater, 2006, 18: 1443

[220] Smatt J H, Spliethoff B, Rosenholm J B, Linden M. Chem Commun, 2004: 2188

[221] Drisko G L, Zelcer A, Luca V, Caruso R A, Soler-Lllia G J A A. Chem Mater, 2010, 22: 4379

[222] Dionigi C, Greco P, Ruani G, Cavallini M, Borgatti F, Biscarini F. Chem Mater, 2008, 20: 7130

[223] Mandlmeier B, Szeifert J M, Fattakhova-Rohlfing D, Amenitsch H, Bein T. J Am Chem Soc, 2011, 133: 17274

[224] Yoldas B E. J Mater Sci, 1986, 21: 1080

[225] Antonelli D D. Microporous Mesoporous Mater, 1999, 33: 209

[226] Blin J L, Léonard A, Yuan Z Y, Gigot L, Vantomme A, Cheetham A K, Su B L. Angew Chem, Int Ed, 2003, 42: 2872

[227] Léonard A, Vantomme A, Bouvy C, Moniotte N, Mariaulle P, Su B L. Nanopages, 2006, 1: 1

[228] Yang X Y, Li Y, Lemaire A, Yu J G, Su B L. Pure Appl Chem, 2009, 81: 2265

[229] Deng W, Toepke M W, Shanks B H. Adv Funct Mater, 2003, 13: 61

[230] Deng W, Shanks B H. Chem Mater, 2005, 17: 3092

[231] Hakim S H, Shanks B H. Chem Mater, 2009, 21: 2027

[232] Hakim S H, Shanks B H. Microporous Mesoporous Mater, 2010, 135: 105

[233] Yuan Z Y, Vantomme A, Léonard A, Su B L. Chem Commun, 2003: 1558

[234] Yuan Z Y, Ren T Z, Su B L. Adv Mater, 2003, 15: 1462

[235] Ren T Z, Yuan Z Y, Su B L. Langmuir, 2004, 20: 1531

[236] Ren T Z, Yuan Z Y, Su B L. Colloids Surf A, 2004, 241: 67

[237] Léonard A, Blin J L, Su B L. Chem Commun, 2003: 2568

[238] Yuan Z Y, Ren T Z, Vantomme A, Su B L. Chem Mater, 2004, 16: 5096

[239] Su B L, Léonard A, Yuan Z Y. C R Chim, 2005, 8: 713

[240] Vantomme A, Léonard A, Yuan Z Y, Su B L. Colloids Surf A 2007, 300: 70

[241] Yuan Z Y, Ren T Z, Azioune A, Pireaux J J, Su B L. Catal Today, 2005, 105: 647

[242] Ren T Z, Yuan Z Y, Azioune A, Pireaux J J, Su B L. Langmuir, 2006, 22: 3886

[243] Yuan Z Y, Ren T Z, Azioune A, Pireaux J J, Su B L. Chem Mater, 2006, 18: 1753

[244] Vantomme A, Yuan Z Y, Su B L. New J Chem, 2004, 28: 1083

[245] Vantomme A, Su B L. Stud Surf Sci Catal, 2007, 165: 235

[246] Li X Y, Chen L H, Li Y, Rooke J C, Deng Z, Hu Z Y, Liu J, Krief A, Yang XY, Su B L. Microporous Mesoporous Mater, 2012, 152: 110

[247] Li X Y, Chen L H, Li Y, Rooke J C, Wang C, Lu Y, Krief A, Yang X Y, Su B L. J Colloid Interf Sci, 2012, 368, 128

[248] Léonard A, Su B L. Chem Commun, 2004: 1674

[249] Ren T Z, Yuan Z Y, Su B L. Stud Surf Sci Catal, 2007, 165: 287

[250] Ren T Z, Yuan Z Y, Su B L. Chem Commun, 2004: 2730

[251] Léonard A, Su B L. Colloids Surf A, 2007, 300: 129

[252] Dapsens P Y, Hakim S H, Su B L, Shanks B H. Chem Commun, 2010, 46: 8980
[253] Li Y, Yang X Y, Tian G, Vantomme A, Yu J G, Tendeloo G V, Su B L. Chem Mater, 2010, 22: 3251

[254] Collins A, Carriazo D, Davis S A, Mann S. Chem Commun, 2004: 568

[255] Su B L, Vantomme A, Surahy L, Pirard R, Pirard J P. Chem Mater, 2007, 19: 3325

[256] Yang X Y, Li Y, Van Tendeloo G V, Xiao F S, Su B L. Adv Mater, 2009, 21: 1368

[257] Lemaire A, Wang Q Y, Wei Y, Su B L. J Colloids Interf Sci, 2011, 363: 511

[258] Lemaire A, Su B L. Langmuir, 2010, 26: 17603

[259] Lemaire A, Su B L. Microporous Mesoporous Mater, 2011, 142: 70

[260] Lemaire A, Rooke J C, Chen L H, Su B L. Langmuir, 2011, 27: 3030

[261] Barakat T, Rooke J C, Tidahy H L, Hosseini M, Cousin R, Lamonier J F, Giraudon J M, Weireld G D, Su B L, Siffert S. ChemSusChem, 2011, 4: 1420

[262] Tidahy H L, Siffert S, Lamonier J F, Zhilinskaya E A, Aboukaïs A, Yuan Z Y, Vantomme A, Su B L, Canet X, Deweireld G, Frère M, N'Guyen T B, Giraudon J M, Leclercq G. Appl Catal A, 2006, 310: 61

[263] Tidahy H, Siffeit S, Lamonier J F, Zhilinskaya E A, Aboukaïs A, Yuan Z Y, Vantomme A, Su B L, Canet X, Deweireld G, Frère M. Stud Surf Sci Catal, 2007, 160: 201

[264] Rooke J C, Barakat T, Siffert S, Su B L. Catal Today, 2011,192: 183

[265] Tidahy H L, Hosseni M, Siffert S, Cousin R, Lamonier J F, Aboukais A, Su B L, Giraudon J M, Leclercq G. Catal Today, 2008, 137: 335

[266] Giraudon J M, Nguyen T B, Leclercq G, Siffert S, Lamonier J F, Aboukais A, Vantomme A, Su B L. Catal Today, 2008, 137: 379

[267] Lamonier J F, Nguyen T B, Franco M, Siffert S, Cousin R, Li Y, Yang X Y, Su B L, Giraudon J M. Catal Today, 2011, 164: 566

[268] Finol M F, Rooke J, Su B L, Trentesaux M, Giraudon J M, Lamonier J F. Catal Today, 2011,192: 154

[269] Gennequin C, Lamallem M, Cousin R, Siffert S, Idakiev V, Tabakova T, Aboukais A, Su B L.J Mater Sci, 2009, 44: 6654

[270] Barakat T, Rooke J C, Franco M, Cousin R, Lamonier J F, Giraudon J M, Su B L, Siffert S. Eur J Inorg Chem, 2012, 16: 2812

[271] Barakat T, Rooke J C, Genty E, Cousin R, Siffert, S, Su B L. Energy Environ Sci, 2012, doi:10.1039/c2ee22859a

[272] Toberer E S, Joshi A, Seshadri R. Chem Mater, 2005, 17: 2142

[273] Masing G Z. Anorg Allg Chem, 1921, 118: 293

[274] Erlebacher J, Aziz,M J, Karma A,Dimitrov N, Sieradzki K. Nature, 2001, 410: 450

[275] Raney M. US 1563787. 1952

[276] Suzuki Y, Kondo N, Ohji T. J Am Ceram Soc, 2003, 86: 1128

[277] Singh R S, Grimes C A, Dickey E C. Mater Res Innov, 2002, 5: 178

[278] Kim H, daRosa C, Boaro M, Vohs,J M, Gorte R J. J Am CeramSoc, 2002, 85: 1473

[279] Suzuki Y, Yamada T, Sakakibara S, Ohji T. Ceram Eng Sci Proc, 2000, 21: 19

[280] Levitz P, Ehret G, Sinha S K, Drake J M. J Chem Phys, 1991, 95: 6151

[281] Toberer E S, Seshadri R. Chem Commun, 2006: 3159

[282] Panda M, Seshadri R, Gopalakrishnan J. Chem Mater, 2003, 15: 1554

[283] Wiley J B, Kaner R B. Science, 1992, 255: 1093

[284] Wallace C H, Reynolds T K, Kaner R B. Chem Mater, 1999, 11: 2299

[285] Mandal T K, Gopalakrishnan J. J Mater Chem, 2004, 14: 1273

[286] Toberer E S, Löfvander J P, Seshadri R. Chem Mater, 2006, 18:1047

[287] Donnay G, Pawson, D L. Science, 1969, 166: 1147

[288] Panda M, Rajamathi M, Seshadri R. Chem Mater, 2002, 14: 4762

[289] Toberer, E S, Weaver J C, RameshaK, Seshadri R. Chem Mater, 2004, 16: 2194 


\section{Graphical Abstract}

Chin. J. Catal., 2013, 34: 22-47 doi: 10.1016/S1872-2067(11)60507-X

Synthesis and applications of hierarchically porous catalysts

LI Xiaoyun, SUN Minghui, ROOKE Joanna Claire, CHEN Lihua*, SU Bao-Lian*

Wuhan University of Technology, China;

University of Namur (FUNDP), Belgium;

University of Cambridge, $U K$

Hierarchically porous catalysts: recent developments with the main focus on the synthesis strategies that are available as well as their application in catalysis.

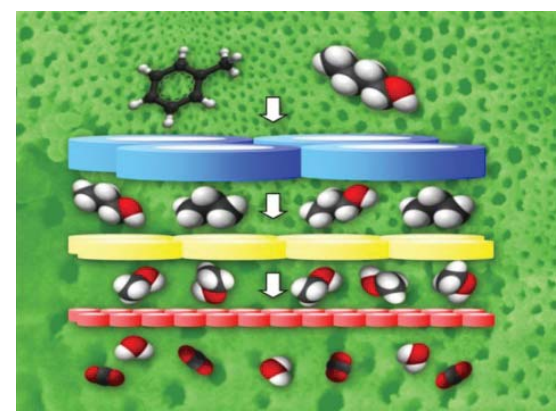

[290] Toberer E S, Epping J D, Chmelka B F, Seshadri R. Chem Mater, 2006, 18: 6345

[291] TobererE S, Schladt T D, Seshadri R. J Am Chem Soc, 2006,128: 1462

[292] Zhou H, Zhu S, Hibino M, Honma I, Ichihara M. Adv Mater, 2003, 15: 2107

[293] Chang H, Joo S H, Pak C. J Mater Chem, 2007, 17: 3078

[294] Liu H J, Cui W J, Jin L H, Wang C X, Xia Y Y.J Mater Chem, 2009, 19 : 3661

[295] Fang B, Zhou H, Honma I. J Phys Chem B, 2006, 110: 4875

[296] Lee J, Kim J, Hyeon T. Adv Mater, 2006, 18: 2073

[297] Stein A, Wang Z, Fierke M A. Adv Mater, 2009, 21: 265

[298] Chai G S, Shin I S, Yu J S. Adv Mater, 2004, 16: 2057

[299] Fang B, Kim J H, Kim M, Yu J S. Chem Mater, 2009, 21: 789

[300] Woo S W, Dokko K, Nakano H, Kanamura K. J Mater Chem, 2008, 18: 1674

[301] Deng Y H, Liu C, Yu T, Liu F, Zhang F Q, Wan Y, Zhang L J, Wang C C, Tu B, Webley, P A, Wang H T, Zhao D Y. Chem Mater, 2007, 19: 3271

[302] Zhang S, Chen L, Zhou S, Zhao D Y, Wu L M. Chem Mater, 2010, 22 :
3433

[303] Lee J, Sohn K, Hyeon T.J Am Chem Soc, 2001, 123: 5146

[304] Lee J, Sohn K, Hyeon T. Chem Commun, 2002: 2674

[305] Lee J, Kim J, Hyeon T. Chem Commun, 2003: 1138

[306] Lee J, Kim J, Kim J, Jia H, Kim M I, Kwak J H, Jin S, Dohnalkova A, Park H G, Chang H N, Wang P, Grate J W, Hyeon T. Small, 2005, 1: 744

[307] Taguchi A, Smatt J H, Lindén M. Adv Mater, 2003, 15: 1209

[308] Wang Z Y, Li F, Ergang N S, Stein A. Chem Mater, 2006, 18: 5543

[309] Yoon S B, Sohn K, Kim J Y, Yu J S, Hyeon T. Adv Mater, 2002, 14: 19

[310] Kim M, Sohn K, Na H B, Hyeon T. Nano Lett, 2002, 2: 1383

[311] Yu J S, Yoon S B, Lee Y J, Yoon K B. J Phys Chem B, 2005, 109: 7040

[312] Song C, Du J P, Zhao J H, Feng S A, Du G X, Zhu Z P. Chem Mater, 2009, 21: 1524

[313] Pérez-Ramírez J, Mitchell S, Verboekend D, Milina M, Michels N L, Krumeich F, Marti N, Erdmann M. ChemCatChem, 2011, 3: 1731

[314] Li Y, Fu Z Y, Su B L. Adv Funct Mater, 2012, 22: 4634

[315] Wang C, Huang S Z, Wang L, Deng Z, Jin J, Chen L H, ZZheng X F, Li Y, Su B L. RSC $A d v$, 2013, DOI: 10.1039/c2ra22202g

\section{多级孔催化剂的合成及应用}

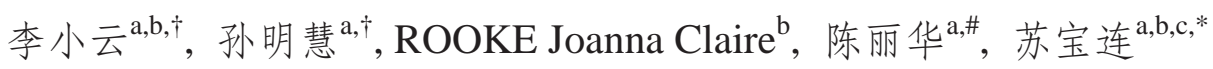

a武汉理工大学材料复合新技术国家重点实验室, 湖北武汉 430070

${ }^{\mathrm{b}}$ 那慕尔大学(FUNDP) 无机材料化学实验室 (CMI), 比利时那慕尔

${ }^{\mathrm{c}}$ 剑桥大学化学系, 英国剑桥

摘要: 系统总结了多级孔分子笁、多级孔金属氧化物和多级孔碳基材料等多级孔催化剂材料的研究进展, 主要阐述了多级孔催化 剂材料已有的制备方法及其在催化领域中的应用.

关键词: 多级孔结构; 分子篮; 金属氧化物; 碳基

收稿日期: 2012-12-20. 接受日期: 2012-12-29. 出版日期: 2013-01-20.

*通讯联系人. 电话: +32-81-724531; 传真: +32-81-725414; 电子信箱: bao-lian.su@fundp.ac.be

\#通讯联系人. 电话/传真: (027)87855322; 电子信箱: chenlihua@whut.edu.cn

十同等贡献作者, 共同第一作者.

基金来源：长江学者和创新团队发展计划(IRT1169); 欧盟第七框架项目(REDUGAZ).

本文的英文电子版由Elsevier出版社在ScienceDirect上出版(http://www.sciencedirect.com/science/journal/18722067). 